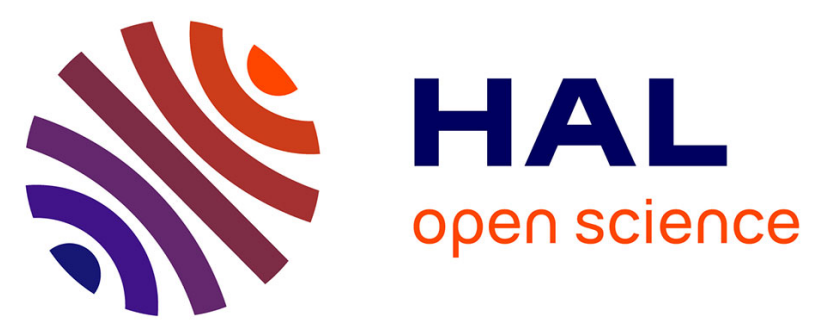

\title{
Experimental and Computational Investigations on Highly Syndioselective Styrene-Ethylene Copolymerization Catalyzed by Allyl ansa-Lanthanidocenes
}

Elisa Louyriac, Eva Laur, Alexandre Welle, Aurélien Vantomme, Olivier Miserque, Jean-Michel Brusson, Laurent Maron, Jean-François Carpentier, Evgueni Kirillov

\section{- To cite this version:}

Elisa Louyriac, Eva Laur, Alexandre Welle, Aurélien Vantomme, Olivier Miserque, et al.. Experimental and Computational Investigations on Highly Syndioselective Styrene-Ethylene Copolymerization Catalyzed by Allyl ansa-Lanthanidocenes. Macromolecules, 2017, 50 (24), pp.9577-9588. 10.1021/acs.macromol.7b01969 . hal-01695557

\section{HAL Id: hal-01695557}

\section{https://hal-univ-rennes1.archives-ouvertes.fr/hal-01695557}

Submitted on 13 Apr 2018

HAL is a multi-disciplinary open access archive for the deposit and dissemination of scientific research documents, whether they are published or not. The documents may come from teaching and research institutions in France or abroad, or from public or private research centers.
L'archive ouverte pluridisciplinaire HAL, est destinée au dépôt et à la diffusion de documents scientifiques de niveau recherche, publiés ou non, émanant des établissements d'enseignement et de recherche français ou étrangers, des laboratoires publics ou privés. 


\section{Experimental and Computational Investigations on Highly Syndioselective}

\section{Styrene-Ethylene Copolymerization Catalyzed by Allyl ansa-Lanthanidocenes}

Elisa Louyriac, ${ }^{\mathrm{a}, \S}$ Eva Laur, ${ }^{\mathrm{b}, \S}$ Alexandre Welle,${ }^{\mathrm{c}}$ Aurélien Vantomme, ${ }^{\mathrm{c}}$ Olivier Miserque,${ }^{\mathrm{c}}$ Jean-Michel Brusson, ${ }^{\mathrm{d}}$ Laurent Maron, ${ }^{\mathrm{a},{ }^{*}}$ Jean-François Carpentier ${ }^{\mathrm{b},{ }^{*}}$ and Evgueni Kirillov, ${ }^{\mathrm{b}, *}$

a Université de Toulouse, CNRS, INSA, UPS, LPCNO, UMR 5215, 135 avenue de Rangueil, F-31077 Toulouse Cedex 4, France

${ }^{\mathrm{b}}$ Université de Rennes 1, CNRS, Institut des Sciences Chimiques de Rennes, UMR 6226, F35042 Rennes Cedex, France

${ }^{\mathrm{c}}$ Total Raffinage Chimie Research, Zone Industrielle C, B-7181 Feluy, Belgium

d Total S.A., Direction scientifique, 24 Cours Michelet, F-92069 Paris La Défense Cedex, France

\section{Graphical Abstract}

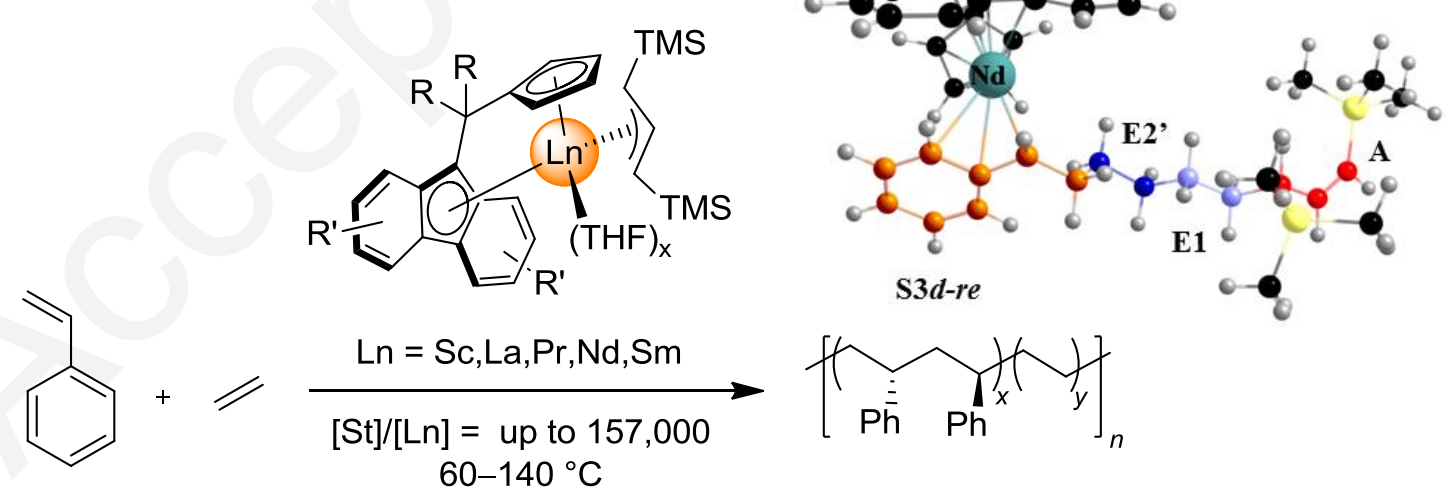

\footnotetext{
$\S$ Those two authors contributed equally to the manuscript, respectively for the theoretical and experimental parts.

*Corresponding authors: laurent.maron@irsamc.ups-tlse.fr; jean-francois.carpentier@univ-rennes1.fr; evgueni.kirillov@univ-rennes1.fr
} 


\section{Abstract}

The syndioselective copolymerization of styrene with ethylene (in bulk or in aliphatic hydrocarbon solutions, $(n \mathrm{Bu})_{2} \mathrm{Mg}$ as scavenger, $\left.T_{\text {polym }}=60-140{ }^{\circ} \mathrm{C}\right)$ was achieved in the presence of a series of ansa-lanthanidocenes of the type $\left\{\mathrm{R}_{2} \mathrm{C}\left(\mathrm{C}_{5} \mathrm{H}_{4}\right)\left(\mathrm{R}^{\prime} \mathrm{R}^{\prime} \mathrm{Flu}\right)\right\} \mathrm{Ln}(1,3-$ $\left.\mathrm{C}_{3} \mathrm{H}_{3}\left(\mathrm{SiMe}_{3}\right)_{2}\right)(\mathrm{THF})_{x}$ (1-Nd-K-allyl, 2-7-Nd, 2-Sc,La,Sm,Pr). While precursors based on small ionic radius metals (2-Sc) or bearing bulky substituents in 3,6- positions of the fluorenyl moieties (3-Nd, 5-Nd) were poorly or not active under standard polymerization conditions $\left(60{ }^{\circ} \mathrm{C}\right)$, 2-La,Pr,Nd,Sm which bear $2,7-t \mathrm{Bu}_{2}$ substituents on the Flu ligand produced efficiently sPSE materials (productivity $300-400^{+} \mathrm{kg} \cdot \mathrm{mol}(\mathrm{Ln})^{-1} \cdot \mathrm{h}^{-1},[r]^{5}=71 \%$; controlled amount of ethylene inserted in the range $1-15 \mathrm{~mol} \%)$. Under harsher conditions $\left(T_{\mathrm{polym}}=\right.$ $100-140{ }^{\circ} \mathrm{C},[\mathrm{St}]_{0} /[\mathrm{Nd}]_{0}=40000-147000$ equiv), 2-Nd produced similar sPSE materials with a productivity increased by one order of magnitude (up to $5430 \mathrm{~kg} \cdot \mathrm{mol}(\mathrm{Nd})^{-1} \cdot \mathrm{h}^{-1}$ ). Theoretical DFT investigations including the solvent model, performed on the first three insertion steps for the benchmark catalysts $\left\{\left(\mathrm{Me}_{2} \mathrm{C}\left(\mathrm{C}_{5} \mathrm{H}_{4}\right)(\mathrm{Flu})\right\} \mathrm{Nd}\left(\mathrm{C}_{3} \mathrm{H}_{5}\right)(\mathrm{THF})\right.$ (I), the putative 1-Nd and the most effective 2-Nd, allowed to corroborate the nature of the obtained copolymers, with ethylene units randomly distributed within long sPS sequences. These studies established also that the presence of bulky substituents on the fluorenyl ligands is crucial in the activity but the nature of the substituents on the allyl group has no effect on the chemistry and the nature of the resulting styrene-ethylene copolymer, but only influences the initiation step in which the first ethylene insertion will be more or less favored with respect to the styrene insertion. 


\section{Introduction}

Syndiotactic polystyrene (sPS) is an attractive engineering plastic potentially usable for many industrial applications due to its fast crystallization rate, low permeability to gases, low dielectric constant and good chemical and temperature resistance. ${ }^{1,2,3}$ However, its high melting point $\left(270{ }^{\circ} \mathrm{C}\right)$ and its brittleness are the two main drawbacks limiting its processability. To tackle this issue, several strategies have been envisaged: blending or postmodification of sPS, polymerization of functionalized styrene derivatives, or copolymerization of styrene with other monomers. ${ }^{4,5}$ The latter approach was found effective and versatile to fine-tune the properties of $\mathrm{sPS}^{6}{ }^{6}$ more particularly via syndioselective copolymerization of styrene with ethylene. ${ }^{7}$ The copolymerization of those two monomers is quite challenging due to their strikingly different reactivity. As a result, most of the group 4 catalysts active for sPS production only provided "ethylene-styrene interpolymers" (ESI), featuring no stereoregularity and amounts of incorporated styrene below 50mol\%. Those issues were overcome by the development of group 3 catalysts, independently disclosed by our group ${ }^{8}$ and by Hou and co-workers. ${ }^{9}$ Yet, the number of effective catalytic systems for SPSE synthesis remains quite limited to date. ${ }^{10}$

Very recently, we reported on the synthesis and catalytic investigations of a new series of neutral ansa-lanthanidocene catalysts for the production of sPS; ${ }^{11}$ a thorough DFT study of these systems highlighted the different factors governing the formation of sPS. ${ }^{11}$ In this new contribution, we describe the syndioselective copolymerization of styrene with ethylene using this latter series of complexes and demonstrate that some of them feature improved catalytic performances as compared to the current state-of-the-art (Scheme 1). For the first time, the parameters that control syndioselective styrene-ethylene copolymerization were investigated also by DFT computations. These calculations contributed to a better understanding of the 
mechanism and determining the main underlying factors of the effectiveness of some complexes.
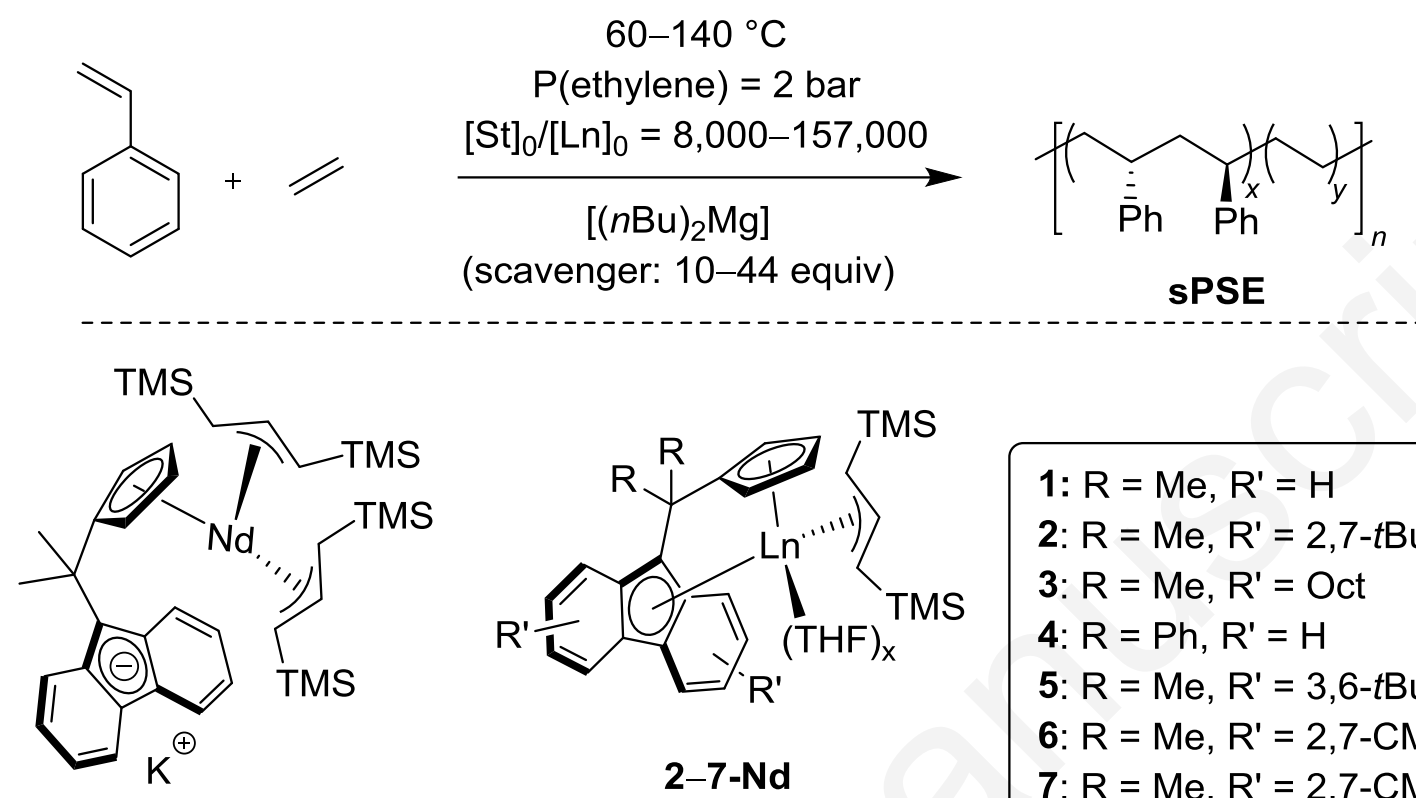

1-Nd-K-allyl

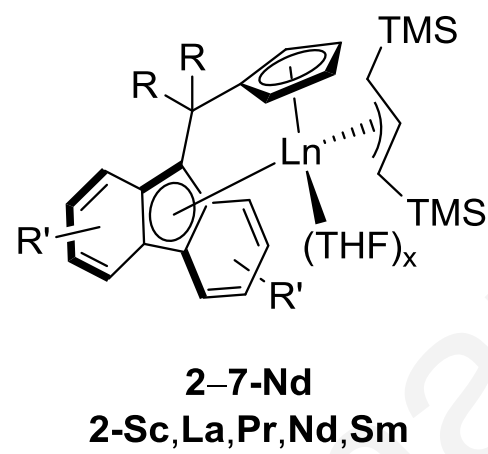
1: $\mathrm{R}=\mathrm{Me}, \mathrm{R}^{\prime}=\mathrm{H}$
2: $R=M e, R^{\prime}=2,7-t B u$
3: $R=M e, R^{\prime}=$ Oct
4: $\mathrm{R}=\mathrm{Ph}, \mathrm{R}^{\prime}=\mathrm{H}$
5: $R=M e, R^{\prime}=3,6-t B u$
6: $\mathrm{R}=\mathrm{Me}, \mathrm{R}^{\prime}=2,7-\mathrm{CMe}_{2} \mathrm{Ph}$
7: $\mathrm{R}=\mathrm{Me}, \mathrm{R}^{\prime}=2,7-\mathrm{CMePh}_{2}$

Scheme 1. Allyl $\{\mathrm{Cp} / \mathrm{Flu}\}$ ansa-lanthanidocenes used as single-component catalysts for highly syndioselective styrene-ethylene copolymerization.

\section{Results and Discussion}

Styrene-Ethylene Copolymerizations Catalyzed by Allyl Ansa-Lanthanidocenes. Styrene/ethylene copolymerizations catalyzed by complexes 1-Nd-K-allyl, 2-Nd-7-Nd, 2-Sc, 2-La, 2-Sm and 2-Pr were first screened under similar conditions (Table 1, entries 1-11). As already described for styrene homopolymerization, ${ }^{11}$ the reactions were best conducted using a few equiv of $(n \mathrm{Bu})_{2} \mathrm{Mg}$ as scavenger, to prevent catalyst decomposition by trace impurities, especially at low catalyst loading and high temperature (vide infra). This dialkylmagnesium appeared to be a poor chain transfer agent under those conditions and did not affect the reaction mechanism nor the properties of the produced sPSE copolymers. ${ }^{11}$ 
As we have demonstrated in the previous study, ${ }^{11}$ substitution on the fluorenyl moiety of the ligand has a strong influence on copolymerization productivities. Complexes 3-Nd and 5-Nd, bearing bulky substituents at the 3,6- positions of the fluorenyl ring, were not or poorly active. 1-Nd-K-allyl and 4-Nd, which bear no substituents on the fluorenyl ring, exhibited moderate productivities and $\mathbf{2 - N d}$, which holds tert-butyl substituents on remote 2,7positions, proved to be the most active within the $\mathrm{Nd}$ series (non-optimized productivity > $400 \mathrm{~kg}(\mathrm{sPSE}) \cdot \mathrm{mol}(\mathrm{Nd})^{-1} \cdot \mathrm{h}^{-1}$, entry 2). Compared to 2-Nd, complexes 6-Nd and 7-Nd showed lower productivities and afforded SPSE copolymers with a higher ethylene content (thus affecting the calculation of syndioselectivity which appeared, at first sight, lower due to more abundant St-E enchainments) (entries 2 and 6-7). The latter observation suggests that introduction of substituents bulkier than $t \mathrm{Bu}$, namely cumyl or $\mathrm{Ph}_{2} \mathrm{MeC}-$, at the 2,7- positions of the fluorenyl ligand favors insertion of a small monomer ethylene rather than styrene.

The nature of the metal center played also a key role. Complex 2-Sc was nearly inactive whereas 2-Pr and 2-La afforded sPSE copolymer with productivities of ca. 300 $\mathrm{kg} \cdot \mathrm{mol}(\mathrm{Ln})^{-1} \cdot \mathrm{h}^{-1}$. Under those non-discriminating conditions, full styrene conversion was reached when using complex $\mathbf{2 - S m}$, as observed with its neodymium analogue 2-Nd.

Substantial improvement of the productivity values was obtained under more forcing and demanding copolymerization conditions (entries 12-17). Increasing both the temperature of polymerization up to $140{ }^{\circ} \mathrm{C}$ and the monomer-to-catalyst ratio up to 40000 allowed to reach productivities above $1,000 \mathrm{~kg}(\mathrm{sPSE}) \cdot \mathrm{mol}(\mathrm{Ln})^{-1} \cdot \mathrm{h}^{-1}$. 2-Nd gave $1400-1700$ $\mathrm{kg}(\mathrm{sPSE}) \cdot \mathrm{mol}(\mathrm{Nd})^{-1} \cdot \mathrm{h}^{-1}$, affording a highly syndiotactic copolymer $\left([r]^{5}=54-61 \%\right)$ with a relatively narrow dispersity value $\left(\bigoplus_{M}=2.4\right)$, despite the elevated polymerization temperature (entries 12 and 13). Similar results were observed using 2-Pr, even though it appeared to be somewhat less active and stereoselective than its $\mathbf{N d}$ analogue. Better productivities in the range $1867-2265 \mathrm{~kg}(\mathrm{sPSE}) \cdot \mathrm{mol}(\mathrm{Sm})^{-1} \cdot \mathrm{h}^{-1}$ were observed with $2-\mathrm{Sm}$ but the syndiotacticity 
of the copolymer significantly dropped $\left([r]^{5}=32-35 \%\right)$. Such a marked discrepancy between the stereoselectivity of $\mathbf{2 - N d}$ and $\mathbf{2 - S m}$ was not observed for the copolymerizations performed at $60{ }^{\circ} \mathrm{C}$ (compare entries 2, 10 and 11 with entries $12-17$ ). Overall, these results are in line with those already described for syndioselective styrene homopolymerization, ${ }^{11}$ and highlight

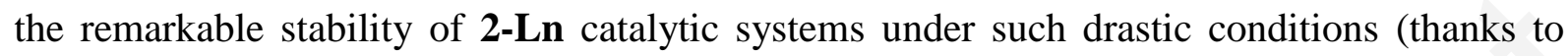
$(n \mathrm{Bu})_{2} \mathrm{Mg}$ as scavenger). The productivities of these systems are comparable with those of the most active cationic scandium-based systems reported for syndiospecific styrene/ethylene copolymerization. ${ }^{8,10}$

The most productive and syndioselective catalyst, $\mathbf{2}$-Nd, was tested on a 10-fold larger production scale (i.e., on a half-kg styrene) in bulk conditions at $100{ }^{\circ} \mathrm{C}$ in a closed reactor; five different experiments with variable amounts of ethylene (vide infra) were conducted and returned improved productivities in the range $2730-5430 \mathrm{~kg}(\mathrm{sPSE}) \cdot \mathrm{mol}(\mathrm{Nd})^{-1} \cdot \mathrm{h}^{-1}$ (entries 18-22). Under these bulk conditions, molecular weights of the resulting copolymers were somewhat higher than those obtained at a lower (bench) scale in 50:50 v/v mixtures of styrene/hydrocarbon solvent $\left(M_{\mathrm{n}}=43000-62000 \mathrm{~g} \cdot \mathrm{mol}^{-1}\right.$ vs. $M_{\mathrm{n}}=33000 \mathrm{~g} \cdot \mathrm{mol}^{-1}$, respectively) and the polydispersities were also narrower $\left(\bigoplus_{M}=1.4-2.5\right)$. These data highlight the significant impact of the process conditions on both the catalytic system productivities and characteristics of the polymers. 
Table 1. Styrene-ethylene copolymerizations catalyzed by 1-Nd-K-allyl, 2-7-Nd and 2-

\section{Sc, $\mathbf{L a}, \mathbf{S m}, \mathbf{P r}^{a}$}

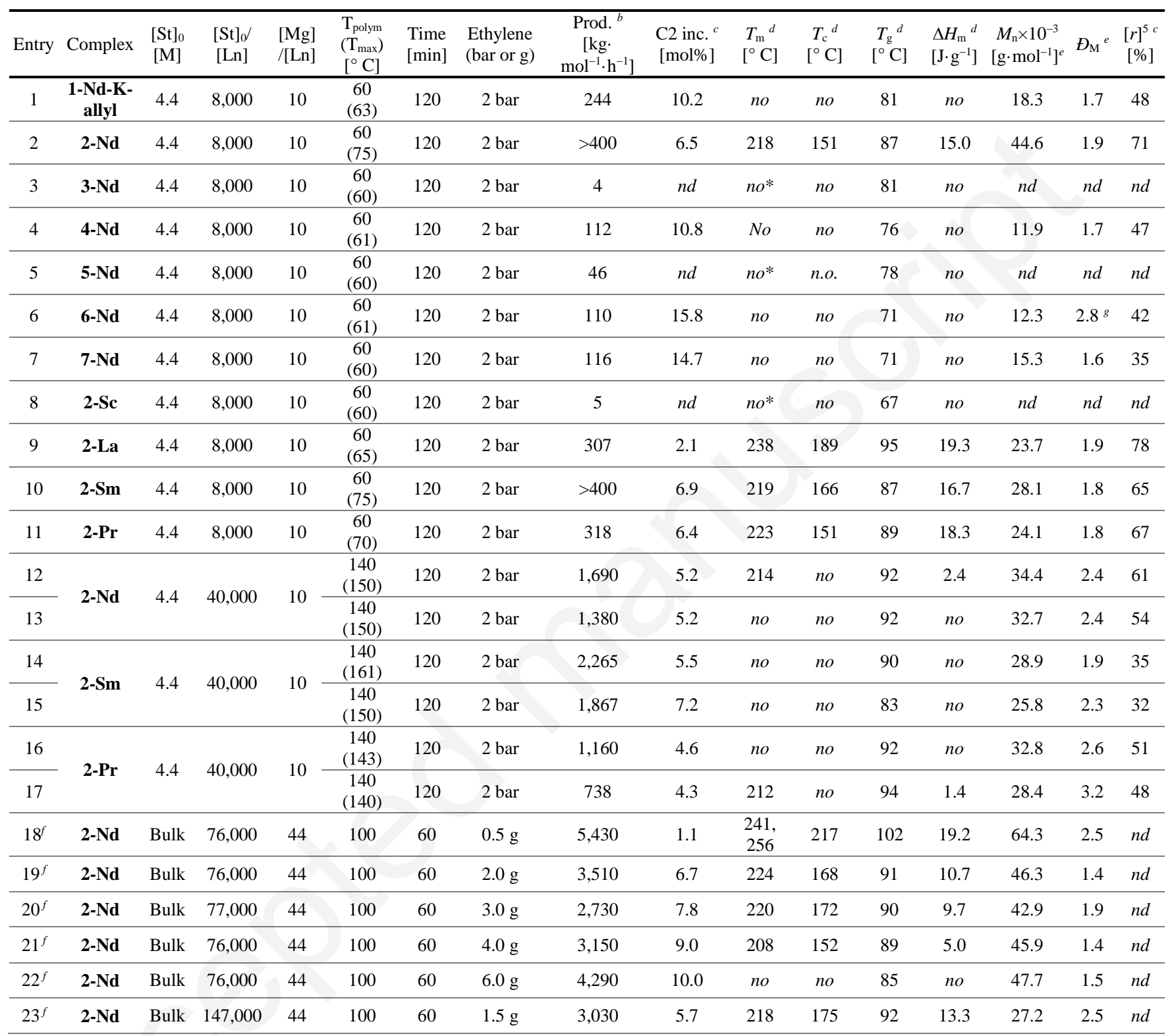

${ }^{a}$ General conditions unless otherwise stated: $10-54 \mu \mathrm{mol}$ of Ln complex; [styrene] $=4.4 \mathrm{M}$ (in cyclohexane at $60{ }^{\circ} \mathrm{C}$ or $n$ dodecane at $140{ }^{\circ} \mathrm{C}$ ) or in bulk (no solvent); Pethylene $=2$ bar; styrene purified through neutral alumina, stirring on $\mathrm{CaH}_{2}$, trapto-trap vacuum distillation and stored in the fridge of the glovebox on $3 \AA$ molecular sieves; $n d$ : not determined; no: not observed. ${ }^{b}$ Productivity calculated over the whole reaction time. ${ }^{c}$ Determined by ${ }^{13} \mathrm{C}$ NMR spectroscopy. ${ }^{d}$ Determined by DSC from second run. ${ }^{e}$ Determined by SEC at $135{ }^{\circ} \mathrm{C}$ in $1,2,4$-trichlorobenzene. ${ }^{f}$ Reactions conducted in a closed 2-L reactor on $500 \mathrm{~g}$ styrene without solvent; ethylene introduced in one shot at the beginning of the polymerization $(0.5-6 \mathrm{~g}) .^{g}$ Bimodal distribution. ${ }^{* 13} \mathrm{C}$ NMR spectroscopy analyses revealed atactic polystyrene. ${ }^{12}$

The initial styrene-to-ethylene ratio was also varied by changing the amount of ethylene introduced at the beginning of the polymerization (entries 18-22; see Experimental part). The ethylene content in the copolymer can be hence easily tuned, allowing the 
production of a range of sPSE materials containing from 1.1 to $10 \mathrm{~mol} \%$ of ethylene. DSC measurements showed that the melting transition temperature and the glass transition of those materials are closely related to the quantity of ethylene incorporated, decreasing almost linearly with the quantity of ethylene incorporated (Figure 1).

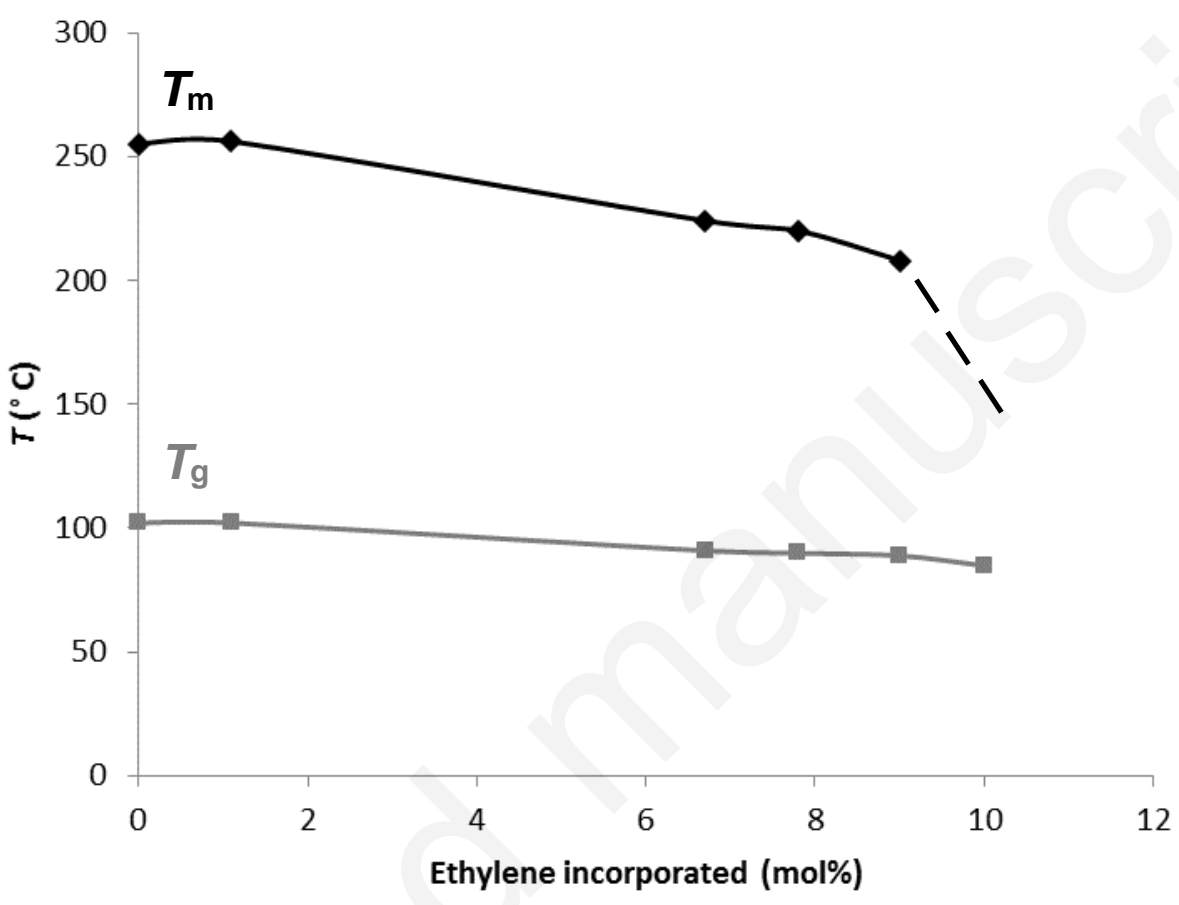

Figure 1. Melting $\left(T_{\mathrm{m}}\right)$ and glass $\left(T_{\mathrm{g}}\right)$ transition temperatures of sPSE materials prepared in bulk in the presence of complex 2-Nd as a function of the amount of ethylene incorporated (entries 18-22).

Copolymer microstructure. The microstructures of the sPSE copolymers were determined by ${ }^{13} \mathrm{C}$ NMR spectroscopy. The aliphatic regions of the ${ }^{13} \mathrm{C}$ NMR spectra of two styrene-rich copolymers with different ethylene contents are illustrated in Figure 2. The general pattern of those spectra is consistent with the one previously reported for styreneethylene copolymers obtained with $\left\{\left(\mathrm{Me}_{2} \mathrm{C}\left(\mathrm{C}_{5} \mathrm{H}_{4}\right)(\mathrm{Flu})\right\} \mathrm{Nd}_{(}\left(\mathrm{C}_{3} \mathrm{H}_{5}\right)(\mathrm{THF})(\mathbf{I})\right.$ as catalyst. ${ }^{8}$ This unequivocally indicates that copolymers synthesized in the presence of 1-Nd-K-allyl, 
2-4-5-7-Nd and 2-La,Sm,Pr have similar microstructures, i.e. essentially single ethylene units randomly distributed within syndiotactic polystyrene chains. Typical ${ }^{13} \mathrm{C}\left\{{ }^{1} \mathrm{H}\right\} \mathrm{NMR}$ spectra exhibit resonances assigned to long polystyrene sequences SSSS or SSSE $(\delta 45.0$, 44.3-43.6, $41.7 \mathrm{ppm})$, or SES sequence with isolated ethylene units ( $\delta 46.6,37.8,37.6,25.3$, $25.0 \mathrm{ppm})$. No signal for long PE sequences ( $\delta$ ca. $28 \mathrm{ppm})$ was observed, even at significant ethylene content.

Those ${ }^{13} \mathrm{C}\left\{{ }^{1} \mathrm{H}\right\}$ NMR spectra were recorded using an inverse-gated-decoupling sequence in order to accurately determine the amount of ethylene incorporated. As only isolated units of ethylene were detected, the amount of ethylene incorporated was determined integrating the signal of the ipso carbon (polystyrene sequences, $\delta 145.8 \mathrm{ppm}$ ) and the signals at 37-38 ppm corresponding to the secondary carbons $\mathbf{S}_{\alpha \gamma}$.

The analysis of the spectra area corresponding to the resonance of the secondary carbon $S_{\alpha}$ of PS sequences also allowed quantifying the syndiotacticity at the hexad level (Figure 3). The relative intensity of the rrrrr hexad signal was obtained after deconvolution and integration of all the signals in this area. This means that not only the presence of others hexads $m r r r r, r m r r r$ and $r r m r r$ but also the presence of other unassigned sequences (in particular, those that are the consequence of S-E junctions, and presumably as well hexads with meso diads) were considered for the calculation of $[r]^{5}$. The values measured in the present case $\left([r]^{5}=32-78 \%\right)$ are similar to those previously reported in the case of sPSE materials obtained with $\mathbf{I}\left(P_{\mathrm{r}}>0.81,[r]^{5}>35 \%\right.$; depending on the ethylene content $){ }^{8}$ 


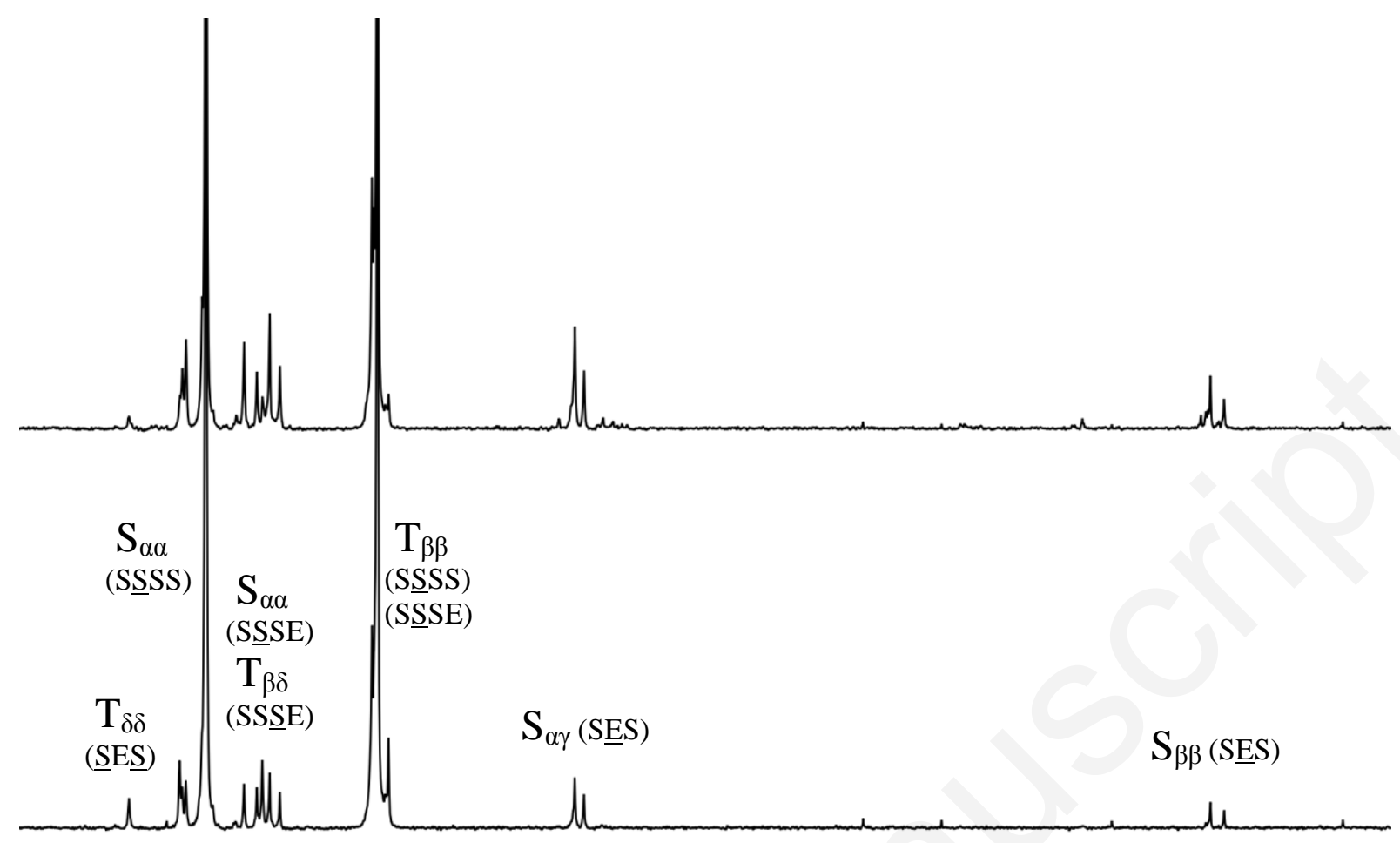

$\begin{array}{lllllllllllllllllllllllllll}48 & 47 & 46 & 45 & 44 & 43 & 42 & 41 & 40 & 39 & 38 & 37 & 36 & \begin{array}{c}35 \\ \mathrm{f} 1\end{array}(\mathrm{ppm}) & 34 & 33 & 32 & 31 & 30 & 29 & 28 & 27 & 26 & 25 & 24 & 23 & 22\end{array}$

Figure 2. Aliphatic region of the ${ }^{13} \mathrm{C}\left\{{ }^{1} \mathrm{H}\right\}$ NMR spectra $\left(125 \mathrm{MHz}, 130{ }^{\circ} \mathrm{C}, \mathrm{C}_{6} \mathrm{H}_{3} \mathrm{Cl}_{3} / \mathrm{C}_{6} \mathrm{D}_{6}\right)$ of sPSE copolymers: (top) 93.5 mol\% styrene (Table 1, entry 2), (bottom) 98 mol\% styrene (entry 9).

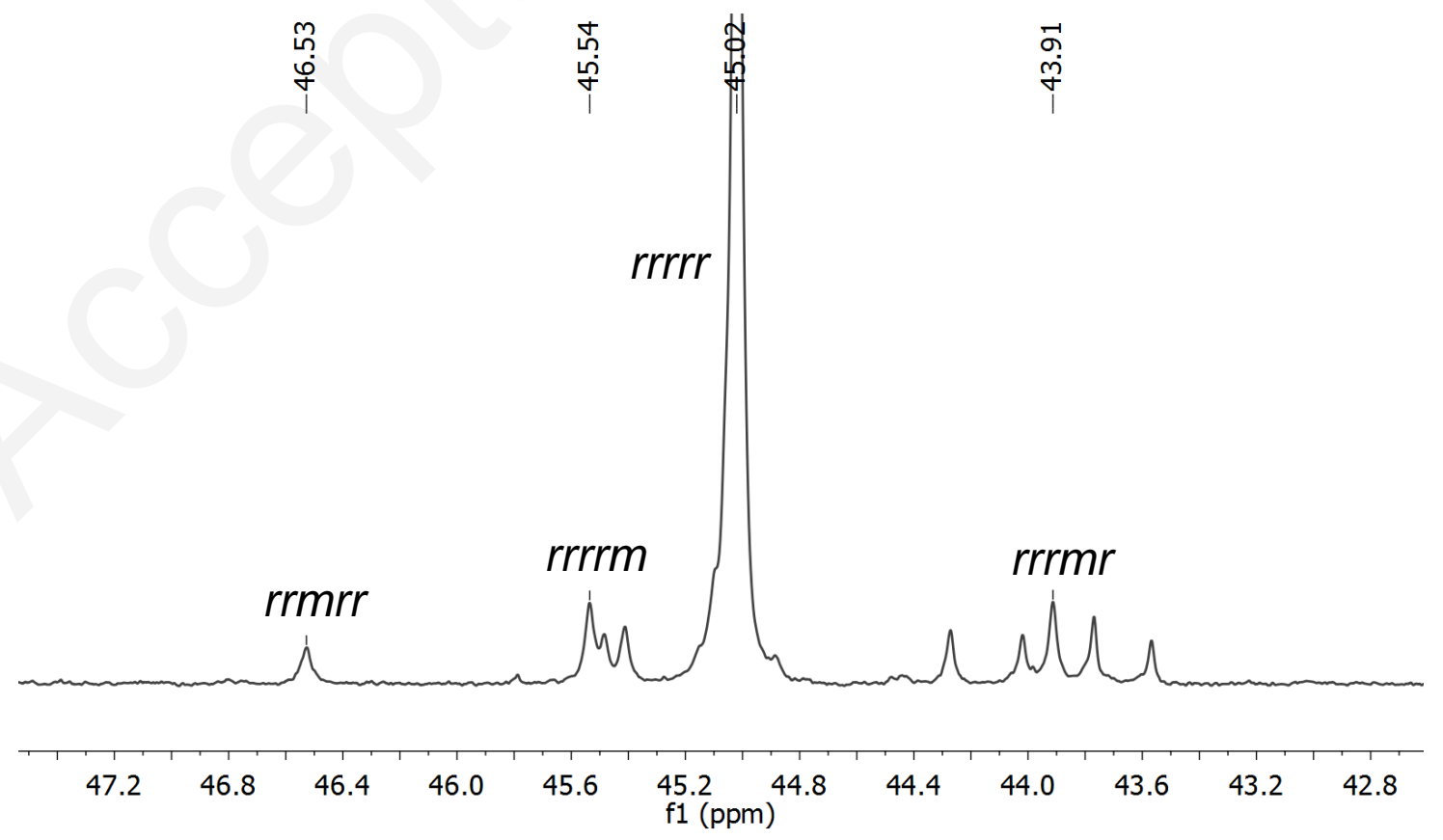


Figure 3. Methylene region of the ${ }^{13} \mathrm{C}\left\{{ }^{1} \mathrm{H}\right\}$ NMR spectrum $\left(125 \mathrm{MHz}, 130{ }^{\circ} \mathrm{C}\right.$, $\mathrm{C}_{6} \mathrm{H}_{3} \mathrm{Cl}_{3} / \mathrm{C}_{6} \mathrm{D}_{6}$ ) of a sPSE copolymer (98 mol\% styrene; Table 1, entry 9).

Computational studies. In the previous study, ${ }^{11}$ DFT calculations including solvent model in the styrene homopolymerization catalyzed by $\left\{\mathrm{Me}_{2} \mathrm{C}\left(\mathrm{C}_{5} \mathrm{H}_{4}\right)(\mathrm{Flu})\right\} \mathrm{Nd}\left(\mathrm{C}_{3} \mathrm{H}_{5}\right)(\mathbf{I})$, the putative $\left\{\mathrm{Me}_{2} \mathrm{C}\left(\mathrm{C}_{5} \mathrm{H}_{4}\right)(\mathrm{Flu})\right\} \mathrm{Nd}\left(1,3-\mathrm{C}_{3} \mathrm{H}_{3}\left(\mathrm{SiMe}_{3}\right)_{2}\right)(\mathbf{1}-\mathrm{Nd})$ and the most effective $\left[\left\{\mathrm{Me}_{2} \mathrm{C}\right.\right.$ $\left.\left.\left(\mathrm{C}_{5} \mathrm{H}_{4}\right)\left(2,7-t \mathrm{Bu}_{2} \mathrm{Flu}\right)\right\} \mathrm{Nd}\left(1,3-\mathrm{C}_{3} \mathrm{H}_{3}\left(\mathrm{SiMe}_{3}\right)_{2}\right)\right]$ (2-Nd) allowed to identify the factors which influence the styrene insertion according to the 2,1-pathway (which is the most favored mode). By using Castro et $a l .{ }^{13}$ method, styrene and ethylene insertions were computed in order to evaluate the effectiveness of catalysts I, 1-Nd and 2-Nd in styrene-ethylene copolymerization and the topology of the obtained SPSE copolymer. At each step, the preference between ethylene and styrene insertions has been examined. Moreover, two chainend stereocontrol mechanims were also considered computationally. For the sake of clarity, the following definitions are considered: insertions that occur on the same enantiotopic site of coordination are denoted as "stationary" mechanism whereas "migratory" insertions refer to the switch of coordination site at each step (Chart 1).

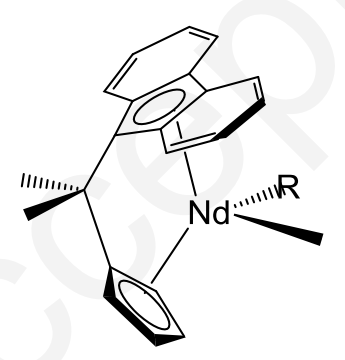<smiles>C=Cc1ccccc1</smiles>

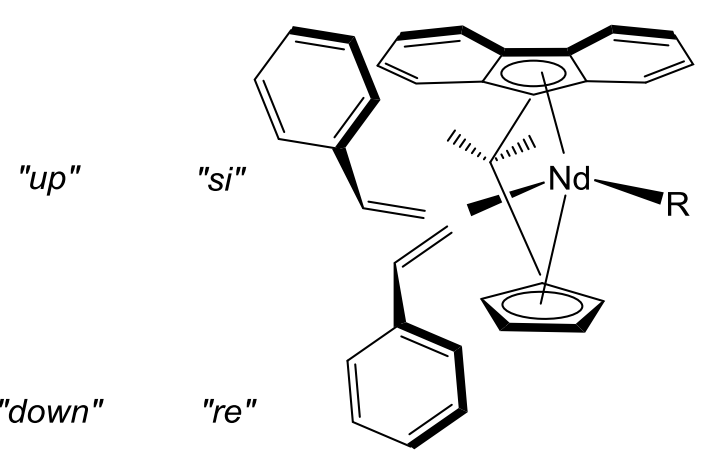

"down"

Chart 1. Nomenclature and orientation modes used for styrene insertion with respect to the ancillary ligand. In this representation, only down-re and up-si styrene coordination modes are depicted, corresponding to the enantiomer of the metal catalyst used for "stationary" 
insertions. The opposite configurations have been employed for "migratory" insertions, viz. down-si and up-re.

\section{DFT investigation of styrene-ethylene copolymerization catalyzed by} $\left\{\mathrm{Me}_{2} \mathrm{C}\left(\mathrm{C}_{5} \mathrm{H}_{4}\right)(\mathrm{Flu})\right\} \mathrm{Nd}\left(\mathrm{C}_{3} \mathrm{H}_{5}\right)$ (I). Complex I, which is highly effective to copolymerize styrene with ethylene while maintaining a high syndiotacticity, ${ }^{8}$ was selected as a benchmark for our theoretical study. Subsequently, it will allow us to highlight the influence of catalyst substituents present on the allyl and fluorenyl ligands on styrene-ethylene copolymerization.

i) First styrene vs. ethylene insertion. Energy profiles were computed for the first ethylene (3-E) and the 2,1-down-re (3d-re) styrene ${ }^{11}$ insertions (Figure 4). From a kinetic point of view, transition state $\mathbf{3 - E}$ is more stable (by $3.3 \mathrm{kcal} \mathrm{mol}^{-1}$ ) than $\mathbf{3 d - r e}$, but this is included within the error range of the method. ${ }^{14,15}$ The first insertion is likely more thermodynamically controlled and in favor of styrene insertion by $4.6 \mathrm{kcal} \mathrm{mol}^{-1}$. The energy difference between 3d-re/3-E is mainly due to the steric hindrance around the metal center (Figure S9). 

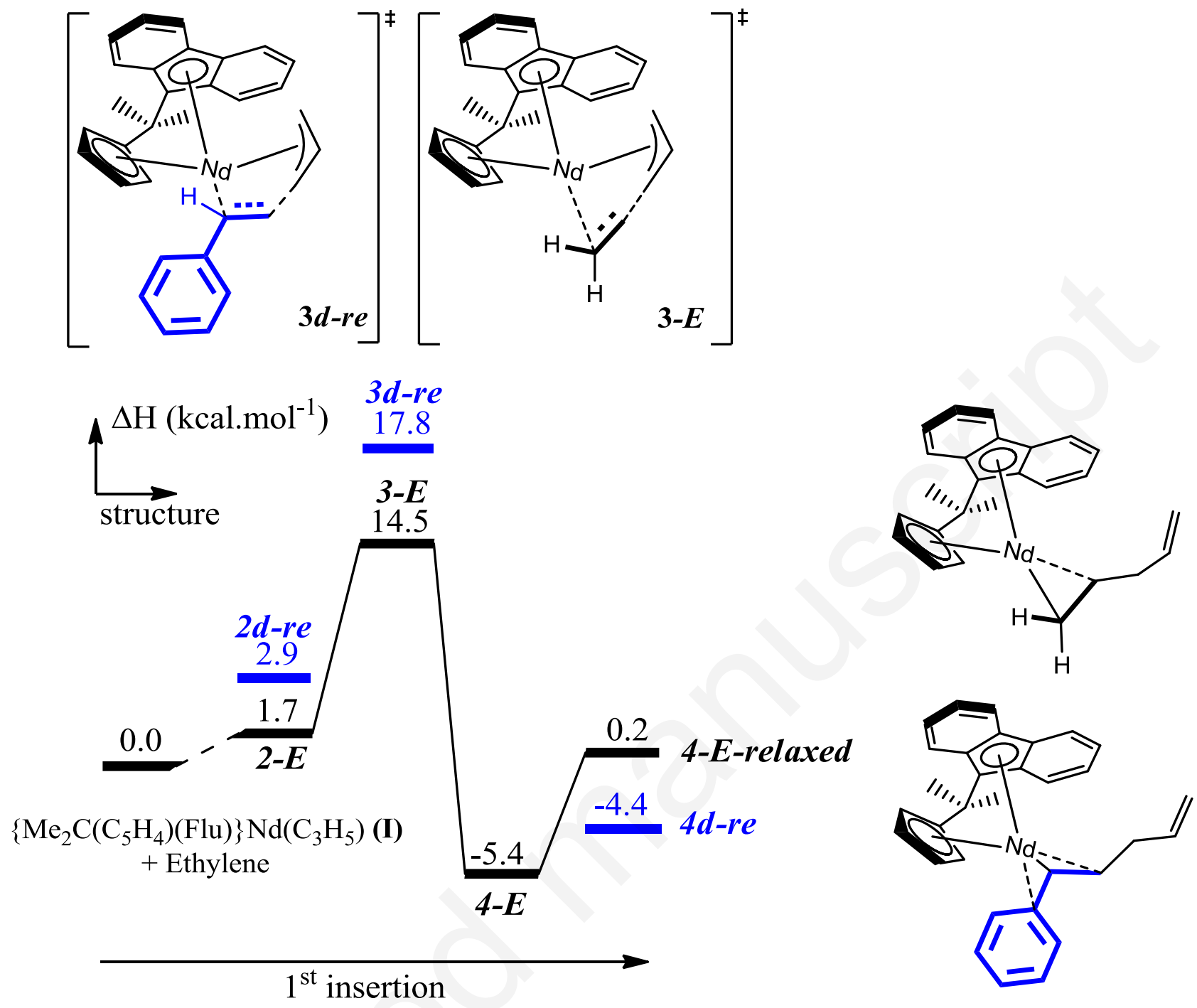

Figure 4. Energetic profiles for the first ethylene (black) and 2,1-down-re styrene (blue) insertions in $\left\{\mathrm{Me}_{2} \mathrm{C}-\left(\mathrm{C}_{5} \mathrm{H}_{4}\right)(\mathrm{Flu})\right\} \mathrm{Nd}\left(\mathrm{C}_{3} \mathrm{H}_{5}\right)(\mathbf{I})$.

Product 4- $\boldsymbol{E}$ obtained following the intrinsic reaction coordinate is extra stabilized by a resulting interaction between the terminal double bond of the allyl ligand and the metal center (Figure S10). The relaxation of the polymer chain leads to an endothermic product 4-Erelaxed (by $0.2 \mathrm{kcal} \mathrm{mol}^{-1}$ ), which is consistent with the fact that formation of an alkyl- from an allyl- complex is thermodynamically unfavorable. 
ii) Second styrene vs. ethylene insertion. As in the first step, 2,1-down-re styrene insertion is thermodynamically favored, second insertions were computed from the product $4 d$-re. The energy profiles were calculated for the stationary $(\mathbf{6}-\boldsymbol{E})$ and migratory $\left(\mathbf{6}-\boldsymbol{E}^{\prime}\right)$ ethylene insertions and for 2,1-up-si (6u-si) stationary styrene insertions (Figure 5).

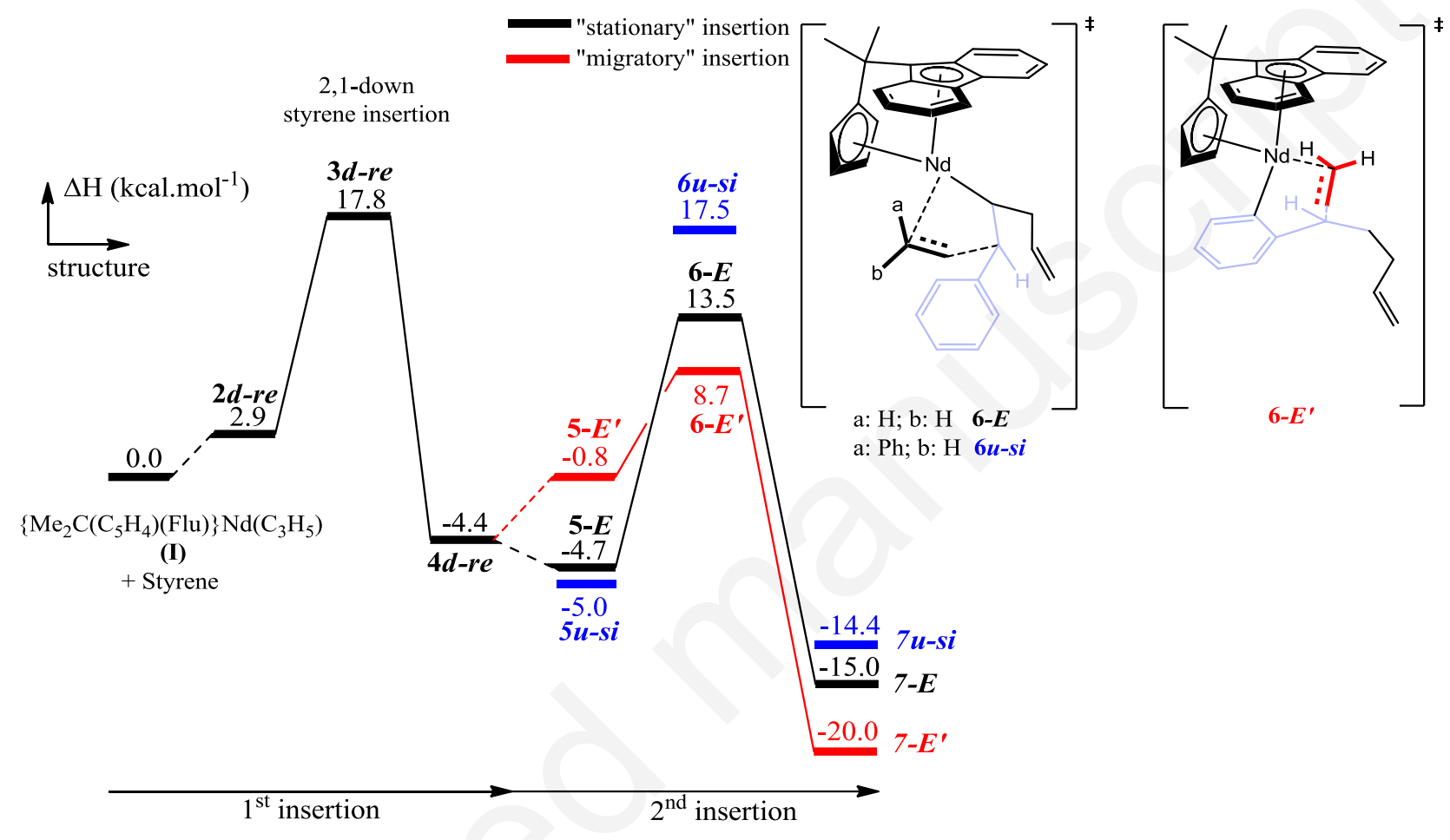

Figure 5. Energetic profiles for the second ethylene (stationary, black, and migratory, red) insertions in $\left\{\mathrm{Me}_{2} \mathrm{C}\left(\mathrm{C}_{5} \mathrm{H}_{4}\right)(\mathrm{Flu})\right\} \mathrm{Nd}\left(\mathrm{C}_{3} \mathrm{H}_{5}\right)(\mathbf{I})$, after a 2,1-down-re styrene first insertion. The second 2,1-up-si stationary styrene insertion (the most stable found in homopolymerization case) is plotted in blue.

From the kinetic point of view, there is a preference for ethylene insertion via $\mathbf{6}-\boldsymbol{E}^{\text {, }}$ which is more stable by $8.8 \mathrm{kcal} \mathrm{mol}^{-1}$ than $\mathbf{6} \boldsymbol{u}$-si and by $4.8 \mathrm{kcal} \mathrm{mol}^{-1}$ than $\mathbf{6 - E}$. This energy difference can be explained by the low steric hindrance in $\mathbf{6 - E}$ ' (Figure S11): the styryl group of the first styrene inserted remains $\eta^{2}$-coordinated instead of the $\eta^{1}$-alkyl forms in $\mathbf{6} \boldsymbol{u}$-si 
$\left(\mathrm{Nd}-\mathrm{C}^{2}=2.97 \AA, \mathrm{Nd}-\mathrm{C}^{i p s o}=2.91 \AA, \mathrm{Nd}-\mathrm{C}^{\text {ortho }}=2.87 \AA\right.$ 的. $\mathrm{Nd}-\mathrm{C}^{2}=2.84 \AA, \mathrm{Nd}-\mathrm{C}^{\text {ipso }}=3.67$

$\AA, \mathrm{Nd}-\mathrm{C}^{\text {ortho }}=3.85 \AA$, respectively) and in $\mathbf{6}-\boldsymbol{E}\left(\mathrm{Nd}-\mathrm{C}^{2}=2.81 \AA, \mathrm{C}^{\text {ipso }}=4.11 \AA, \mathrm{Nd}-\mathrm{C}^{\text {ortho }}=\right.$ $4.62 \AA$ ) (see Chart 2).

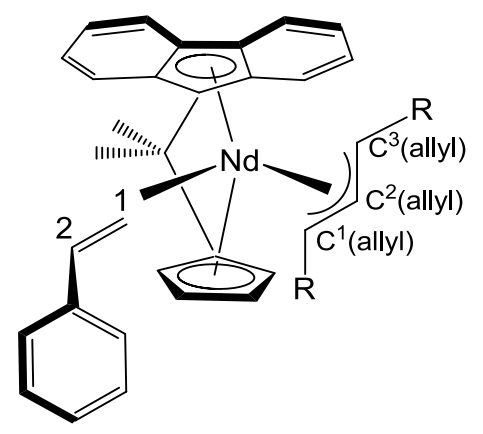

Chart 2. Numbering used for carbon atoms in the allyl ligand.

As regards the $2^{\text {nd }}$ insertion products, the presence of a $\pi$-coordination between the phenyl ring of the first styrene inserted and the metal center further stabilizes the migratory insertion ethylene product $7-\boldsymbol{E}$, by $5.0 \mathrm{kcal} \mathrm{mol}^{-1}$ than for stationary insertion product $7-\boldsymbol{E}$ (Figure S12). Hence, at the second insertion stage, the ethylene monomer will be inserted preferentially, according to the "migratory" mechanism.

ii) Third styrene vs. ethylene insertion. Energy profiles were calculated for the (9-E) ethylene insertion and for 2,1-down-re (9d-re) and 2,1-up-si (9u-si) styrene insertions (Figure $6)$. 


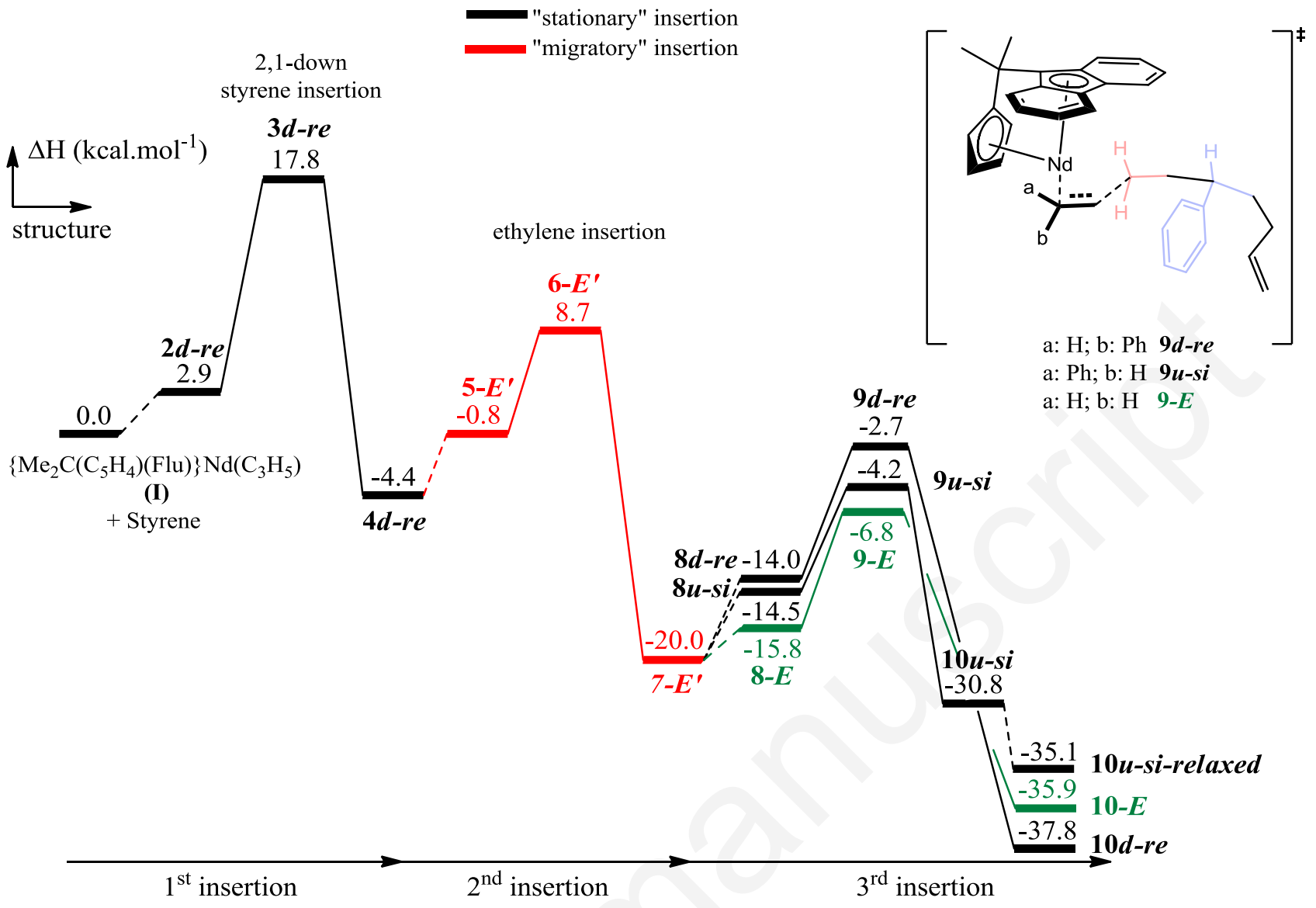

Figure 6. Energetic profiles for the third insertions in $\left\{\mathrm{Me}_{2} \mathrm{C}\left(\mathrm{C}_{5} \mathrm{H}_{4}\right)(\mathrm{Flu})\right\} \mathrm{Nd}\left(\mathrm{C}_{3} \mathrm{H}_{5}\right)(\mathbf{I})$, after a 2,1-down-re styrene first insertion and a migratory ethylene second insertion.

At the third insertion step, there is a slight kinetic preference for insertion of ethylene $\left(\mathbf{9 d - r e} / 9-\boldsymbol{E}=4.1 \mathrm{kcal} \mathrm{mol}^{-1}\right)$ (dark-green), probably related to the decrease of the steric hindrance around the metal center (Figure S13). In all products, the growing chains feature the same orientation, which may explain the same range of their energies (Figure S14).

To obtain further information about the nature of the resulting copolymer, it was crucial to investigate reactional pathways after insertion of two ethylene units and, more generally, after the two units of the same monomer were consecutively inserted.

Ethylene-Ethylene-Ethylene (E-E-E) vs. Ethylene-Ethylene-Styrene (E-E-S). The energy profiles were computed for the third ethylene (9-E) and 2,1-down-re (9d-re) styrene 
insertions, in case where two ethylene monomers were inserted according to the "migratory" insertion mechanism (Figure 7). At this stage, there is no significant kinetic preference between styrene and ethylene insertions $\left(\mathbf{9 d}-\mathbf{r} \boldsymbol{e} / \mathbf{9}-\boldsymbol{E}=3.2 \mathrm{kcal} \mathrm{mol}^{-1}\right)$. The energy difference between the both insertion products $\mathbf{1 0 - E}$ and $\mathbf{1 0 d}$-re is $2.5 \mathrm{kcal} \mathrm{mol}^{-1}$, which is also within the error range of the method. This is reflected in the product structures in which the growing chains are similarly oriented (Figure S16).

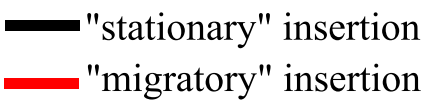

ethylene insertion

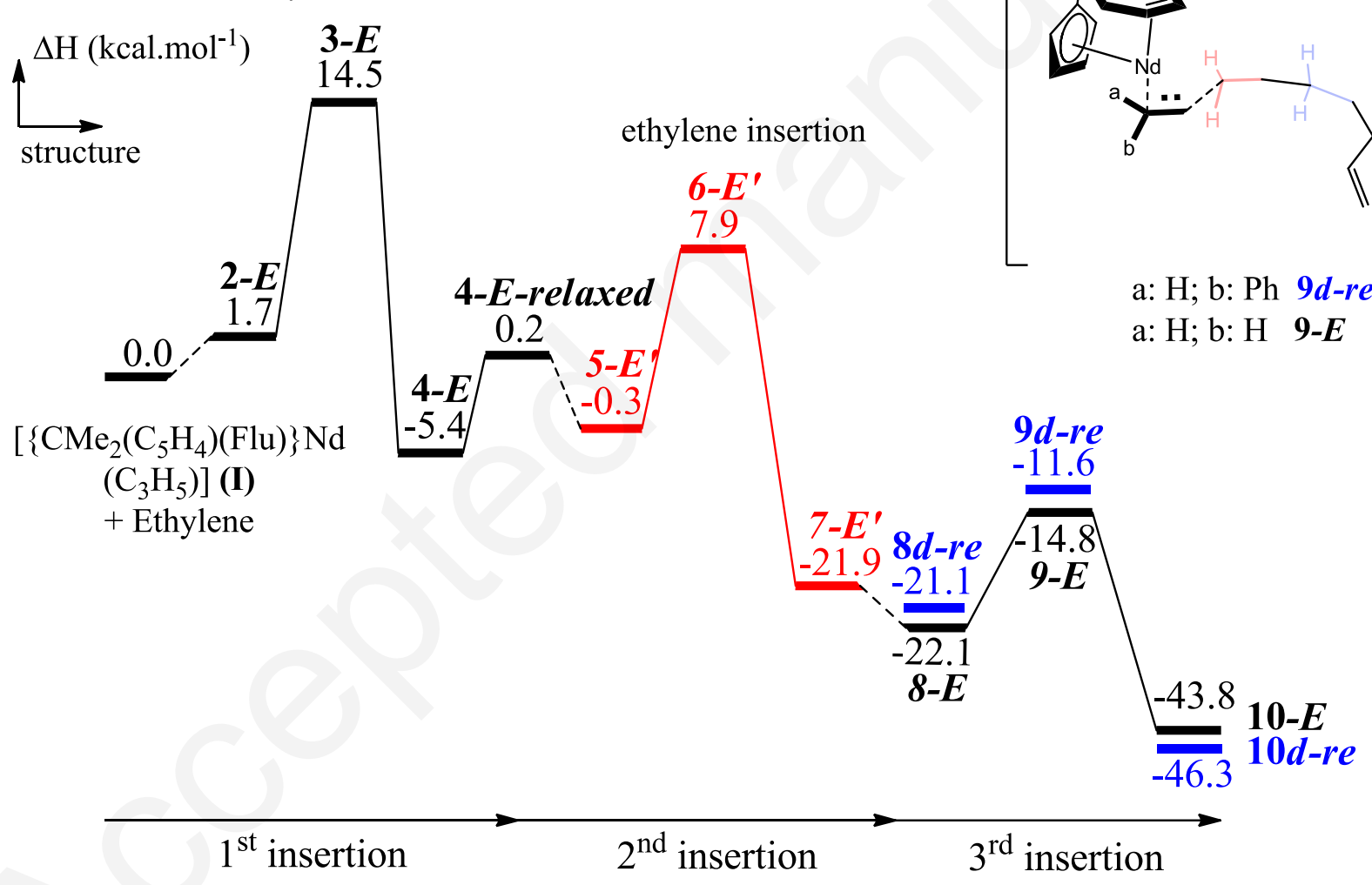

Figure 7. Energetic profiles for the third ethylene insertion in $\left\{\mathrm{Me}_{2} \mathrm{C}\left(\mathrm{C}_{5} \mathrm{H}_{4}\right)(\mathrm{Flu})\right\} \mathrm{Nd}\left(\mathrm{C}_{3} \mathrm{H}_{5}\right)$ (I), after two ethylene insertions. The third 2,1-down-re styrene insertion is plotted in blue. 
Styrene-Styrene-Styrene (S-S-S) vs. Styrene-Styrene-Ethylene (S-S-E). Calculations were similarly performed for the third 2,1-down-re (9d-re) styrene and ethylene (9-E) insertions, after insertion of two styrene monomers (Figure 8). The results match those obtained for the above E-E-E $v s$. E-E-S study: (i) the energy difference $\mathbf{9 d - r e / 9 - E}\left(1.3 \mathrm{kcal} \mathrm{mol}^{-1}\right)$ is included within the error range of the method, and (ii) the growing chains appear to be similar in the transition state and product structures (Figures S17 and S18). This is confirmed by the lack of thermodynamic preference between the two monomers $\left(\mathbf{1 0 d}-\boldsymbol{r e} / \mathbf{1 0}-\boldsymbol{E}=0.5 \mathrm{kcal} \mathrm{mol}^{-1}\right)$.

Overall, the above calculations indicate that, once two units of the same monomer have been inserted, there will be no selectivity at the next stage. In other words, I tends to form random styrene-ethylene copolymers.

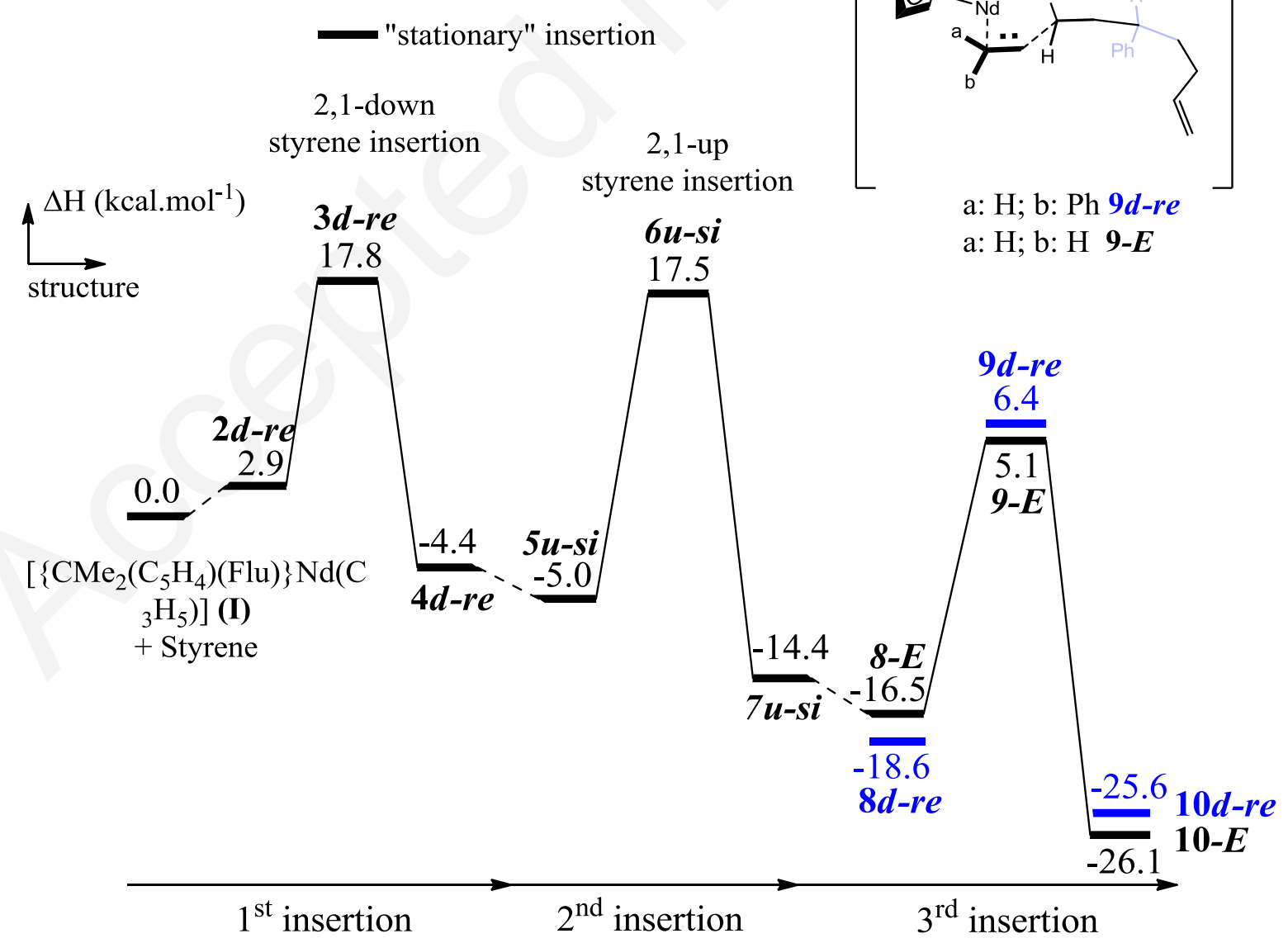


Figure 8. Energetic profiles for the third ethylene insertion in $\left\{\mathrm{Me}_{2} \mathrm{C}\left(\mathrm{C}_{5} \mathrm{H}_{4}\right)(\mathrm{Flu})\right\} \mathrm{Nd}_{(}\left(\mathrm{C}_{3} \mathrm{H}_{5}\right)$ (I), after two styrene insertions according to the "stationary" mode. The third 2,1-down-re styrene insertion (the most stable found in homopolymerization case) is plotted in blue.

DFT investigation of styrene-ethylene copolymerization catalyzed by $\left\{\mathrm{Me}_{2} \mathrm{C}\left(\mathrm{C}_{5} \mathrm{H}_{4}\right)(\mathrm{Flu})\right\} \mathrm{Nd}\left(1,3-\mathrm{C}_{3} \mathrm{H}_{3}\left(\mathrm{SiMe}_{3}\right)_{2}\right)(1-\mathrm{Nd})$. In order to obtain information on the influence of $\mathrm{SiMe}_{3}$ substituents of the allyl ligand on styrene-ethylene copolymerization as well as on the nature of the sPSE copolymer obtained, the same study as that for I was carried out for the putative 1-Nd catalyst. The computational results are similar to those highlighted for the non-substituted catalyst I (all reaction profiles and structures are available in the Supporting Information; Figures S19-S33): (i) at the first step, a 2,1-down-re styrene insertion is preferred, followed by an ethylene insertion, and then, a slight preference for this latter monomer at the third step; (ii) after insertion of two same monomer units, there is no clear kinetic or thermodynamic preference between the two monomers.

Hence, the above calculations indicate that the presence of the bulky substituents in the allyl initiating group does not affect the chemistry and the nature of the obtained copolymer: the 1-Nd catalyst tends also to form random styrene-ethylene copolymers. This is consistent with an initiating group which is progressively rejected at the end of the growing polymer chain. It should be noted, however, that the bulky substituents on the allyl ligand induce an increase in the energy of the first insertion barriers (for example 24.5 vs. $14.5 \mathrm{kcal}$ $\mathrm{mol}^{-1}$ for the first ethylene insertion), as this has already been observed for styrene homopolymerization. ${ }^{11}$ This is again due to charge localization on the "wrong" carbon atom of the allyl ligand, that is the one that ensures the interaction with the metal center and therefore provides the nucleophilic assistance, rather than the one that is involved in the $\mathrm{C}-\mathrm{C}$ coupling. 
Furthermore, it is noteworthy that at the first ethylene insertion step in 1-Nd, the alkyl product 4-E-relaxed is thermodynamically favorable (by $-10.3 \mathrm{kcal} \mathrm{mol}^{-1}$ ). This is not consistent with the usual trend that the formation of an alkyl from an allyl compound is disfavored thermodynamically. A charge analysis at the NBO level was then carried out in order to obtain some information about the nature of the allyl ligand in 1-Nd. The charges on the carbon atoms in the $\left(1,3-\mathrm{C}_{3} \mathrm{H}_{3}\left(\mathrm{SiMe}_{3}\right)_{2}\right)$ allyl ligand are $\left[\mathrm{C}^{1}\right.$ (allyl) $(-1.05), \mathrm{C}^{2}$ (allyl) $(-0.23), C^{3}$ (allyl) $\left.(-1.11)\right]$ in $\mathbf{1 - N d , ~ w h e r e a s ~ t h o s e ~ o b t a i n e d ~ i n ~ t h e ~ c a s e ~ o f ~ t h e ~ u n s u b s t i t u t e d ~}$ allyl $\left(\mathrm{C}_{3} \mathrm{H}_{5}\right)$ in $\mathbf{I}$ are $\left[\mathrm{C}^{1}\right.$ (allyl) $(-0.79), \mathrm{C}^{2}$ (allyl) $(-0.26), \mathrm{C}^{3}$ (allyl) $\left.(-0.81)\right]$. Thus, the sterically hindered allyl leads to a charge relocalization at the $\mathrm{C}^{3}$ (allyl) carbon atom. Therefore, this is not a standard allyl in 1-Nd but rather a masked alkyl, explaining why formation of 4-E-relaxed is thermodynamically favorable $\left(-10.3 \mathrm{kcal} \mathrm{mol}^{-1} v s .+0.2 \mathrm{kcal}\right.$ $\mathrm{mol}^{-1}$ in the case of the $\left(\mathrm{C}_{3} \mathrm{H}_{5}\right)$ allyl in $\left.\mathbf{I}\right)$.

DFT investigation of styrene-ethylene copolymerization catalyzed by $\left\{\mathrm{Me}_{2} \mathrm{C}\left(\mathrm{C}_{5} \mathrm{H}_{4}\right)\left(2,7-t \mathrm{Bu}_{2} \mathrm{Flu}\right)\right\} \mathrm{Nd}\left(1,3-\mathrm{C}_{3} \mathrm{H}_{3}\left(\mathrm{SiMe}_{3}\right)_{2}\right)(2-\mathrm{Nd})$. It has been experimentally found that complex 2-Nd with $t \mathrm{Bu}$ groups in 2,7- positions of the fluorenyl ligand exhibits a high productivity of up to $5,430 \mathrm{~kg}(\mathrm{sPSE}) \cdot \mathrm{mol}(\mathrm{Nd})^{-1} \cdot \mathrm{h}^{-1}$ for styrene-ethylene copolymerization. The microstructure of the sPSE copolymers shares the same features as those observed for copolymers obtained with I. DFT calculations were performed to rationalize this influence of the 2,7-t $\mathrm{Bu}_{2}$ groups on the Flu ligand on the reactivity and on the copolymer obtained.

The first and second styrene insertion were computed (see ESI figures S34 and S35) and it was found that, unlike complex I, the migratory styrene insertion is preferred for the $\mathbf{2}$-Nd catalyst over the stationary insertion found for $\mathbf{I}$. This can be attributed to the presence of bulky substituents on the allyl ligand that leads to a change in the polymerization mechanism in order to minimize steric repulsion. 
i) First styrene vs. ethylene insertion. As for above, energy profiles were calculated for the ethylene (3-E) and the 2,1-down-re (3d-re) styrene insertions (Figure 9).
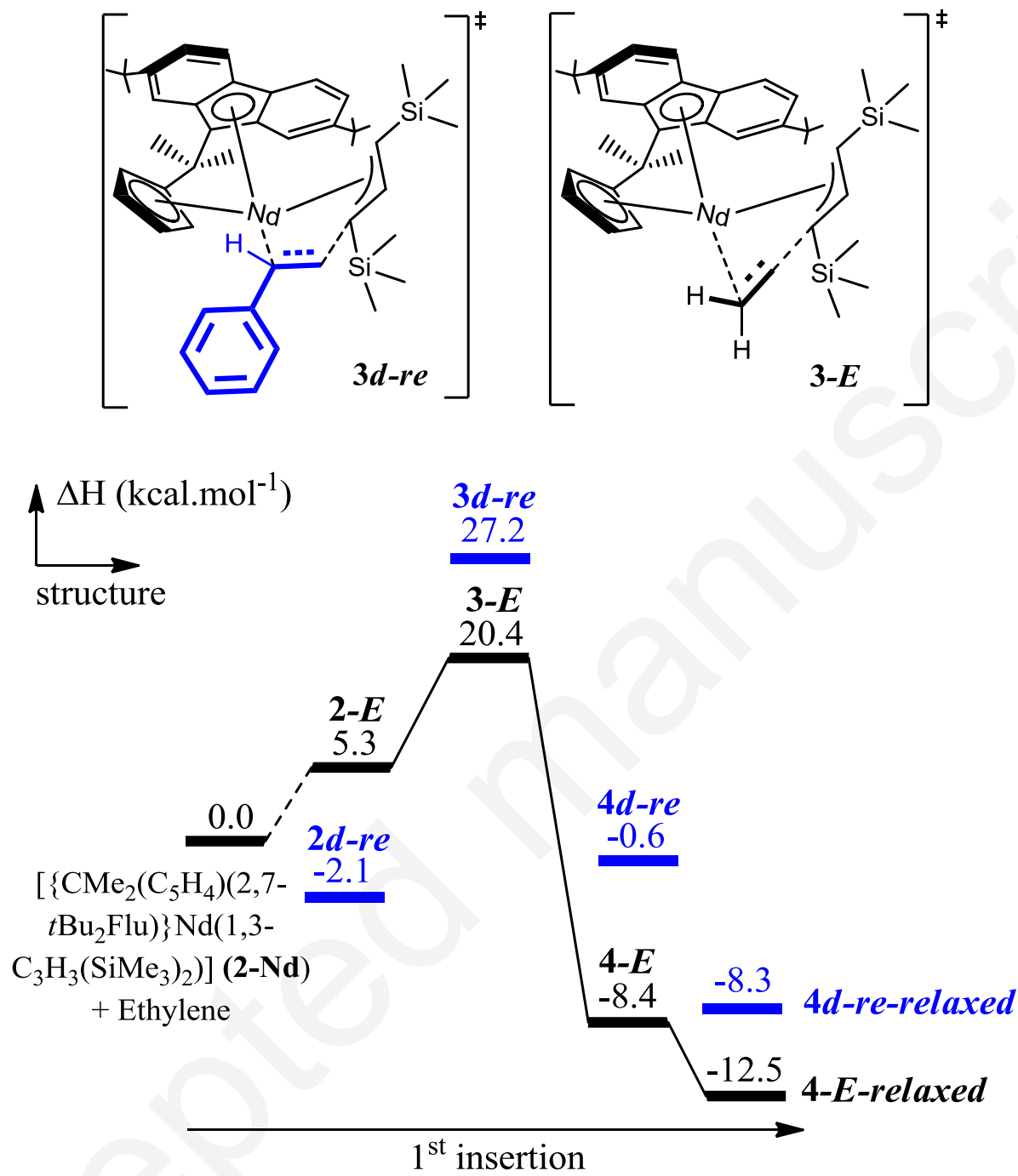

Figure 9. Energetic profiles for the first ethylene (black) and 2,1-down-re styrene (blue) insertions in $\left\{\mathrm{Me}_{2} \mathrm{C}\left(\mathrm{C}_{5} \mathrm{H}_{4}\right)\left(2,7-t \mathrm{Bu}_{2} \mathrm{Flu}\right)\right\} \mathrm{Nd}\left(1,3-\mathrm{C}_{3} \mathrm{H}_{3}\left(\mathrm{SiMe}_{3}\right)_{2}\right)(\mathbf{2}-\mathrm{Nd})$.

From a kinetic point of view, there is a clear preference for $\mathbf{3}-\boldsymbol{E}$ which is more stable by $6.8 \mathrm{kcal} \mathrm{mol}^{-1}$ than $\mathbf{3 d}$-re. This energy difference is due to a repulsion between the $t \mathrm{Bu}$ groups and the $\mathrm{Ph}$ ring of the incoming styrene which tends to destabilize $\mathbf{3 d}$-re compared to 3-E. Moreover, the ethylene insertion barrier is intermediate $\left(\Delta H^{\#}=20.4 \mathrm{kcal} \mathrm{mol}^{-1}\right)$ to those 
calculated for I and 1-Nd $\left(\Delta H^{\#}=14.5\right.$ and $24.5 \mathrm{kcal} \mathrm{mol}^{-1}$, respectively). Indeed, the incorporation of $t \mathrm{Bu}$ substituents counteracts the effect of the $\mathrm{SiMe}_{3}$ on the allyl ligand, which reduces the activation barrier and makes the catalyst more reactive towards ethylene. This is reflected in the NBO charge analysis. The charges on the carbon atoms in the allyl ligand in

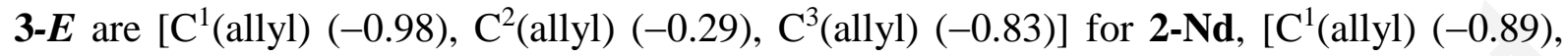
$\mathrm{C}^{2}$ (allyl) (-0.23), $\mathrm{C}^{3}$ (allyl) (-0.95)] for 1-Nd and $\left[\mathrm{C}^{1}\right.$ (allyl) (-0.66), $\mathrm{C}^{2}$ (allyl) (-0.23), $\mathrm{C}^{3}$ (allyl) (-0.61)] for I. In complex 2-Nd, the carbon $\mathrm{C}^{3}$ (allyl) is repulsed by an interaction between the $t \mathrm{Bu}$ and the $\mathrm{SiMe}_{3}$ groups and cannot ensure the nucleophilic assistance. The $\mathrm{C}^{1}$ (allyl) carries the negative charge in order to induce a reaction with the carbon atom of the ethylene monomer and maintains the interaction with the metal center (nucleophilic assistance). This implies that ethylene moves away from the metal center and, thus has a $\mathrm{C}=\mathrm{C}$ double bond less activated $(\mathrm{C}-\mathrm{C}=1.40 \AA$ vs. $1.42 \AA$ in $\mathbf{1 - N d}$ and in $\mathbf{I})$. This charge localization effect allows decreasing the activation barrier compared to the case of complex 1Nd.

In terms of thermodynamics, the alkyl product 4-E-relaxed is favorable (by $-12.5 \mathrm{kcal}$ $\mathrm{mol}^{-1}$ ) which, as pointed out above for $\mathbf{1 - N d}$, is related to the charge of the carbon atoms in the allyl ligand $\left[\mathrm{C}^{1}\right.$ (allyl) $(-1.03), \mathrm{C}^{2}$ (allyl) $(-0.23), \mathrm{C}^{3}$ (allyl) $\left.(-1.15)\right]$ in 2-Nd. In this case, 4-E-relaxed is more stable by $4.2 \mathrm{kcal} \mathrm{mol}^{-1}$ compared to $4 d$-re-relaxed; therefore, ethylene would be preferentially inserted.

ii) Second styrene vs. ethylene insertion. Second insertions were computed after a 2,1-downre styrene insertion. The corresponding energy profiles were calculated for the stationary (6$\boldsymbol{E})$ and migratory (6-E') ethylene insertions and for 2,1-up-re (6u'-re ) migratory styrene insertion (Figure 10). 


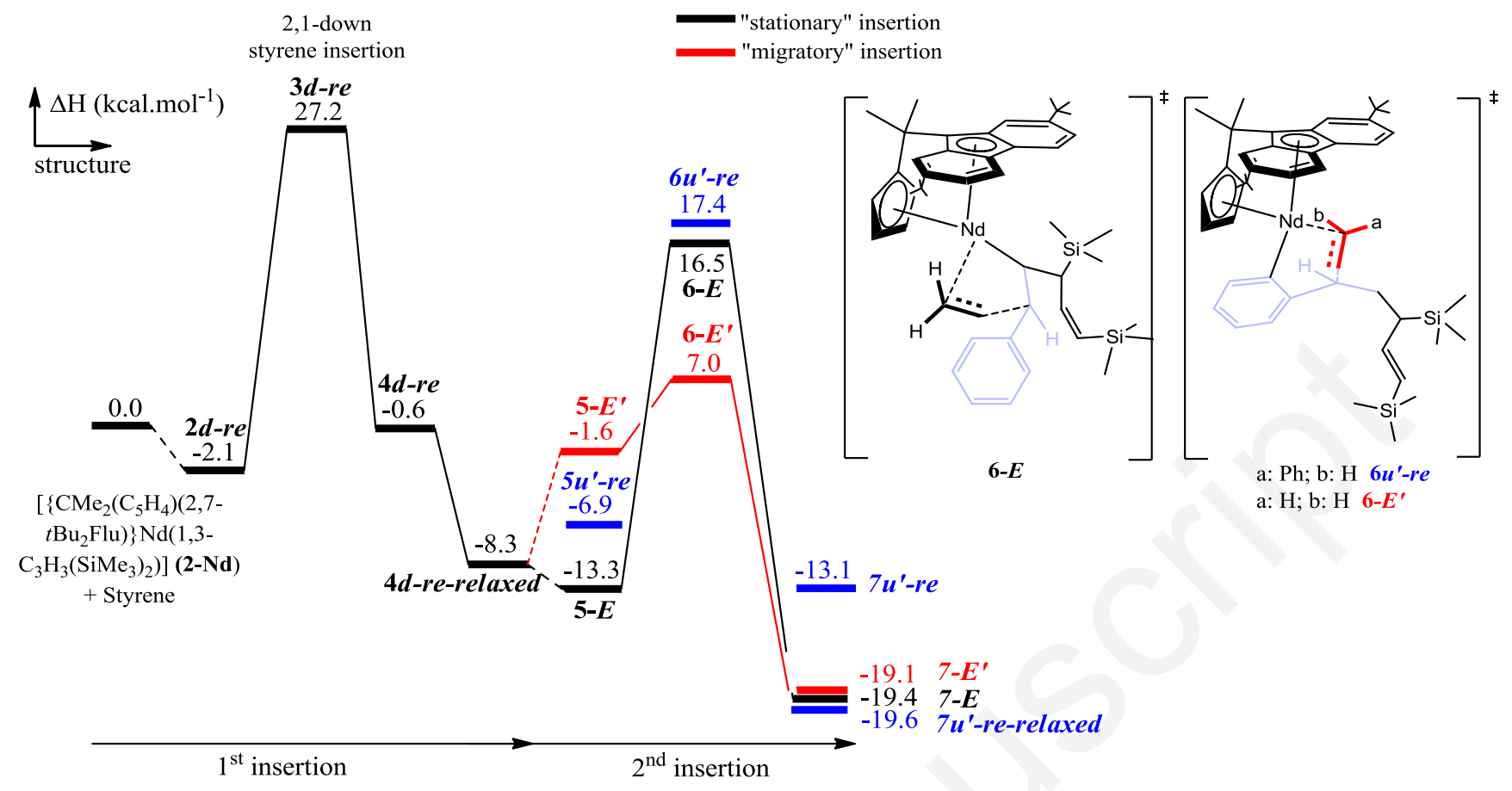

Figure 10. Energetic profiles for the second ethylene (stationary, black, and migratory, red) insertions in $\left\{\mathrm{Me}_{2} \mathrm{C}\left(\mathrm{C}_{5} \mathrm{H}_{4}\right)\left(2,7-t \mathrm{Bu}_{2} \mathrm{Flu}\right)\right\} \mathrm{Nd}\left(1,3-\mathrm{C}_{3} \mathrm{H}_{3}\left(\mathrm{SiMe}_{3}\right)_{2}\right)$ (2-Nd), after a 2,1-down-re styrene first insertion. The second 2,1-up-re migratory styrene insertion (the most stable found in homopolymerization case) is plotted in blue.

The results for the second insertion with $\mathbf{2 - N d}$ are similar to those obtained for the two previous catalysts. Indeed, after a 2,1-down-re styrene insertion, migratory ethylene insertion is kinetically preferred $\left(\mathbf{6} \boldsymbol{u}^{\prime}-\boldsymbol{r} \boldsymbol{e} / \mathbf{6}-\boldsymbol{E}^{\prime}=10.4\right.$ and $\left.\mathbf{6 - E} / \mathbf{6}-\boldsymbol{E}^{\prime}=9.5 \mathrm{kcal} \mathrm{mol}^{-1}\right)$.

These results are quite similar to those obtained for the 1-Nd and I catalysts, suggesting the formation of random copolymers. This conclusion is further strengthened by the results obtained for the third steps (Figures S40 and S41), as no selectivity was found, in line with the formation of random styrene-ethylene copolymers.

In summary, DFT calculations allowed to rationalize the nature of the copolymer obtained as well as the influence of the substituents of the catalyst. The 1,3-trimethylsilyl substituents on the allyl ligand cause (i) a modification of the distribution of the charges on 
the allylic carbon atoms, which makes the first ethylene insertion product thermodynamically favorable, and (ii) an increase in the insertion barriers, related to the steric hindrance and the charge distribution. On the other hand, bulky 2,7-tert-butyl groups on the fluorenyl ligand tend to promote ethylene insertion for the second insertion. This is also related to a charge localization effect.

Finally, for the three catalytic systems studied, no modification in the nature of the obtained copolymer is observed, that is the formation of random styrene-ethylene copolymers with a high syndiotacticity in the PS sequences.

\section{Conclusions}

The performance of a series of allyl ansa-lanthanidocenes of the general formula $\left\{\mathrm{R}_{2} \mathrm{C}\left(\mathrm{C}_{5} \mathrm{H}_{4}\right)\left(\mathrm{R}^{\prime} \mathrm{R}^{\prime} \mathrm{Flu}\right)\right\} \mathrm{Ln}\left(1,3-\mathrm{C}_{3} \mathrm{H}_{3}\left(\mathrm{SiMe}_{3}\right)_{2}\right)(\mathrm{THF})_{x} \quad$ was assessed in styrene-ethylene copolymerization. By using forcing copolymerization conditions, that is a low catalyst loading and relatively high temperature, a high productivity of $5,430 \mathrm{~kg}(\mathrm{sPSE}) \cdot \mathrm{mol}(\mathrm{Nd})^{-1} \cdot \mathrm{h}^{-1}$ was achieved with $\mathbf{2 - N d}$ on a half-kilogram scale, which is comparable with the most active scandium half-sandwich complexes. ${ }^{9}$ The sPSE copolymers thus obtained feature a random microstructure with single ethylene units distributed in highly syndiotactic PS sequences. The ethylene content and thus the thermal properties of the materials can be tuned by the initial comonomer feed.

Theoretical DFT studies allowed rationalizing the random nature of the obtained styrene-ethylene copolymers catalyzed by complexes I, 1-Nd and $\mathbf{2 - N d . ~ T h e ~ c a l c u l a t i o n s ~}$ showed that: (i) $\mathrm{SiMe}_{3}$ substituents on the allyl ligand have an influence on the nature of the first insertion product and notably on the stability of the ethylenic product, and (ii) those on the fluorenyl ligand either make the catalyst more ethylene reactive at the second insertion 
(2,7 substitution) or block the reactivity (3,6 substitution). This last point is essential to explain the good productivity of catalyst 2-Nd for styrene-ethylene copolymerization.

\section{Experimental Section}

General considerations. All experiments were performed under a dry argon atmosphere, using a glovebox or standard Schlenk techniques. Complexes 1-Nd-K-allyl, 2-7-Nd, 2-Sc, 2Y, 2-La, 2-Pr and 2-Sm were synthesized as reported before. ${ }^{11}$ Cyclohexane and $n$-dodecane were distillated from $\mathrm{CaH}_{2}$ and stored over $3 \AA$ AS. Styrene (Fisher Chemical, general purpose grade, stabilized with $10-15 \mathrm{ppm}$ of tert-butylcatechol) was eluted through neutral alumina, stirred and heated over $\mathrm{CaH}_{2}$, vacuum-distilled and stored over $3 \AA$ MS at $-30{ }^{\circ} \mathrm{C}$ under argon. The $(n \mathrm{Bu})_{2} \mathrm{Mg}$ solution $(1.0 \mathrm{M}$ in heptane, Sigma-Aldrich) was used as received. Ethylene (Air Liquide, N35) was used without further purification.

Instruments and measurements. ${ }^{13} \mathrm{C}\left\{{ }^{1} \mathrm{H}\right\}$ NMR and GPC analyses of sPSE samples were performed at the research center of Total Raffinage-Chimie in Feluy (Belgium). ${ }^{13} \mathrm{C}\left\{{ }^{1} \mathrm{H}\right\}$ NMR analyses were run on a Bruker Avance III $500 \mathrm{MHz}$ equipped with a cryoprobe HTDUL in $10 \mathrm{~mm}$ tubes $\left(1,2,4\right.$-trichlorobenzene/ $\left.\mathrm{C}_{6} \mathrm{D}_{6}, 2: 0.5 \mathrm{v} / \mathrm{v}\right)$. GPC analyses were performed in 1,2,4-trichlorobenzene at $135{ }^{\circ} \mathrm{C}$ using PS standards for calibration. Differential scanning calorimetry (DSC) analyses were performed on a Setaram DSC 131 apparatus, under continuous flow of helium and using aluminum capsules. Crystallization temperatures were measured during the first cooling cycle $\left(10^{\circ} \mathrm{C} / \mathrm{min}\right)$, and glass and melting transition temperatures were measured during the second heating cycle $\left(10{ }^{\circ} \mathrm{C} / \mathrm{min}\right)$.

Typical procedure for bench-scale styrene-ethylene copolymerization. In a typical experiment (Table 1, entry 1), a $300 \mathrm{~mL}$ glass high-pressure reactor (TOP-Industrie) was charged with $50 \mathrm{~mL}$ of solvent (cyclohexane or $n$-dodecane) under argon flash and heated at the appropriate temperature by circulating water or oil in a double mantle. Under an ethylene 
flow, styrene $(50 \mathrm{~mL})$, a solution of $(n \mathrm{Bu})_{2} \mathrm{Mg}(0.5 \mathrm{~mL}$ of a $1.0 \mathrm{M}$ solution in heptane $)$ and a solution of pre-catalyst in toluene $(c a .43 \mathrm{mg}$ in $2 \mathrm{~mL}$ ) were introduced. The gas pressure in the reactor was set at 2 atm and kept constant with a back regulator, and the reaction media was mechanically stirred. At the end of the polymerization, the reaction was cooled, vented, and the copolymer was precipitated in methanol (ca. $500 \mathrm{~mL})$; after filtration, it was washed with methanol and dried under vacuum at $60^{\circ} \mathrm{C}$ until constant weight.

Typical procedure for half-kg-scale styrene-ethylene copolymerizations in a closed reactor. In a typical experiment (Table 1, entry 18), a $1 \mathrm{~L}$ high-pressure reactor was charged with $500 \mathrm{~mL}$ of styrene (degassed under nitrogen, stored in the fridge on $13 \mathrm{X}$ molecular sieves and eluted through an alumina column prior to use) under nitrogen flush and heated at the appropriate temperature by circulating oil in a double mantle. An exact amount of ethylene was introduced in one shot in the reactor using an injecting system equipped with a pressure gauge, followed by a solution of $(n \mathrm{Bu})_{2} \mathrm{Mg}(2.5 \mathrm{~mL}$ of a $1.0 \mathrm{M}$ solution in heptane $)$ and the pre-catalyst $(\mathrm{ca} .45 \mathrm{mg})$. The reactor was closed and the reaction mixture was mechanically stirred. At the end of the polymerization, the reaction mixture was cooled, vented, and the copolymer was precipitated in isopropanol (ca. $2 \mathrm{~L}$ ); after filtration, it was washed with isopropanol. Polymer samples were dried in under vacuum in an oven heated at $200{ }^{\circ} \mathrm{C}$.

Computational Details. The calculations were performed at the DFT level of theory using the hybrid functional B3PW91. ${ }^{16,17}$ Neodymium was treated with a large-core Stuttgart-Dresden relativistic effective core potential (RECP) where the $4 f$ electrons are included in core. The RECP was used in combination with its adapted basis set augmented by a set of $f$ polarization function $(\alpha=1.000) .{ }^{18}$ A $6-31+\mathrm{G}(\mathrm{d}, \mathrm{p})$ double $-\zeta$ quality basis set was used for carbon and hydrogen atoms. The Si atoms were described with a Stuttgart-Dresden relativistic effective core potential in combination with its optimized basis set with the 
addition of a $d$ polarization function $(\alpha=0.284) .{ }^{19,20}$ Toluene was chosen as solvent. The model that was used to take into account solvent effects is the SMD solvation model. The solvation energies are evaluated by a self-consistent reaction field (SCRF) approach based on accurate numerical solutions of the Poisson-Boltzmann equation. ${ }^{21}$ All the calculations were carried out with the Gaussian 09 program. ${ }^{22}$ Electronic energies and enthalpies were calculated at $T=298 \mathrm{~K}$. Geometry optimizations were computed without any symmetry constraints and analytical frequency calculations was used to assess the nature of the extrema. The connectivity of the optimized transition states was determined by performing Intrinsic Reaction Coordinates (IRC) calculations. Activation barriers $\Delta H^{\#}$ are defined depending on the sign of $\Delta H_{\text {coord }}$ (see Figure 11). ${ }^{13}$ Electronic charges were obtained by using Natural Population Analysis (NPA) analysis. ${ }^{23}$ NBO analysis ${ }^{23}$ of the neodymium system was done by applying Clark et al. method. ${ }^{24}$
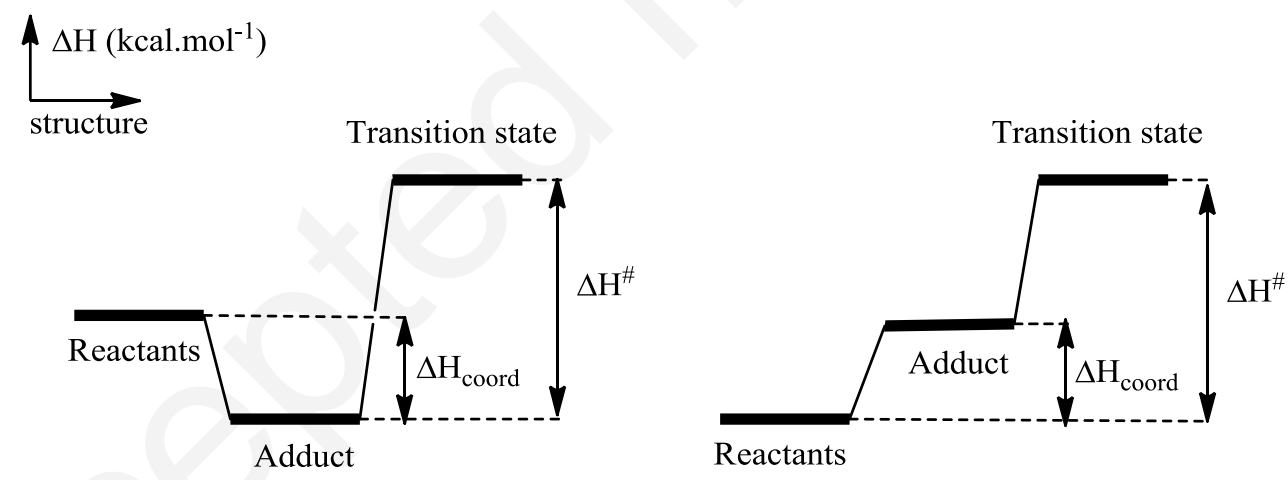

Figure 11. Definition of $\Delta H^{\#}$ depending on the sign of $\Delta H_{\text {coord. }}{ }^{13}$

Acknowledgements. This work was gratefully supported by Total S.A. and Total Research and Technology Feluy (PhD grants to EL and EL). We gratefully thank Katty Den Dauw (Total Research) for performing HT ${ }^{13} \mathrm{C}$ NMR spectroscopic analysis of polymer samples. 
Supporting Information Available. Representative ${ }^{13} \mathrm{C}$ NMR, GPC and DSC data for polymers; Cartesian coordinates and energy optimized stationary points.

The authors declare no conflict of interest.

\section{References and Notes}

1 Ishihara, N.; Kuramoto, M.; Uoi, M. Stereospecific Polymerization of Styrene Giving the Syndiotactic Polymer. Macromolecules 1988, 21, 3356-3360.

2 Malanga, M. Syndiotactic Polystyrene Materials. Adv. Mater. 2000, 12, 1869-1872.

3 Schellenberg, J.; Leder, H.-J. Syndiotactic Polystyrene: Process and Applications. Adv. Polym. Technol. 2006, 25, 141-151.

4 Zinck, P.; Bonnet, F.; Mortreux, A.; Visseaux, M. Functionalization of Syndiotactic Polystyrene. Prog. Polym. Sci. 2009, 34, 369-392.

5 Jaymand, M. Recent Progress in the Chemical Modification of Syndiotactic Polystyrene. Polym. Chem. 2014, 5, 2663-2690.

6 Laur, E.; Kirillov, E.; Carpentier, J.-F. Engineering of Syndiotactic and Isotactic Polystyrene-Based Copolymers via Stereoselective Catalytic Polymerization. Molecules 2017, 22, 594-625.

7 Rodrigues, A.-S.; Carpentier, J.-F. Groups 3 and 4 Single-Site Catalysts for StyreneEthylene and Styrene- $\alpha$-olefin Copolymerization. Coord. Chem. Rev. 2008, 252, 21372154.

8 Rodrigues, A.-S.; Kirillov, E.; Lehmann, C. W.; Roisnel, T.; Vuillemin, B.; Razavi, A.; Carpentier, J.-F. Allyl ansa-lanthanidocenes: Single-Component, Single-Site Ccatalysts for Controlled Syndiospecific Styrene and Styrene-Ethylene (Co)Polymerization. Chem. A Eur. J. 2007, 13, 5548-5565.

9 Luo, Y.; Baldamus, J.; Hou, Z. Scandium Half-Metallocene-Catalyzed Syndiospecific Styrene Polymerization and Styrene-Ethylene Copolymerization: Unprecedented Incorporation of Syndiotactic Styrene-Styrene Sequences in Styrene-Ethylene Copolymers. J. Am. Chem. Soc. 2004, 126, 13910-13911.

10 Li, X.; Wang, X.; Tong, X.; Zhang, H.; Chen, Y.; Liu, Y.; Liu, H.; Wang, X.; Nishiura, M.; He, H.; Lin, Z.; Zhang, S.; Hou, Z. Aluminum Effects in the Syndiospecific 
Copolymerization of Styrene with Ethylene by Cationic Fluorenyl Scandium Alkyl Catalysts. Organometallics 2013, 32, 1445-1458.

11 Laur, E.; Louyriac, E.; Dorcet, V; Welle, A.; Vantomme, A.; Miserque, O.; Brusson, J.M.; Maron, L.; Carpentier, J.-F.; Kirillov, E. Substitution Effects in Highly Syndioselective Styrene Polymerization Catalysts Based on Single-Component Allyl ansa-Lanthanidocenes: An Experimental and Theoretical Study. Macromolecules, 2017, $50,6539-6551$.

12 The presence of atactic PS is likely a result of thermally self-initiated polymerization (Mayo's mechanism). Some of us have previously investigated this process in presence (or absence) of dialkylmagnesium reagents (see: Bogaert, S.; Carpentier, J.-F.; Chenal, T.; Mortreux, A.; Ricart, G. Macromol. Chem. Phys., 2000, 201, 1813-1822) under conditions which are comparable to those reported in the current manuscript, in particular with styrene purified the same way (it is noteworthy that thoroughly purified styrene is much less prone to radical polymerization as there is no "residual" initiator) and reactions performed in bulk styrene. We observed that, at $105{ }^{\circ} \mathrm{C}$, only $18-20 \%$ of atactic PS formed after $5 \mathrm{~h}$; with $5 \mathrm{mmol}$ of $\mathrm{MgR}_{2}$ for $175 \mathrm{mmol}$ of styrene, the resulting aPS had a high molecular weight (typically $M_{\mathrm{n}}=150 \mathrm{~kg} \cdot \mathrm{mol}^{-1}, \mathrm{PDI}=2.4$ ). The reactions reported in the current manuscript were conducted at higher temperatures, but over shorter reactions times. We hence did not expect the formation of significant amounts of atactic PS. This is corroborated by GPC analyses which showed monomodal traces with $M_{\mathrm{n}}$ values in the typical range $12-45 \mathrm{~kg} / \mathrm{mol}$; no significant presence of high MW PS was observed (see the Supp. Info.). Yet, the possible presence of a few $\%$ of aPS in the essentially sPS(E) materials cannot be discarded. Note that during homopolymerization of styrene with the same neodymocene catalysts, it was noted that if $\mathrm{MgR}_{2}$ is not 
introduced to scavenge the reaction medium, uncontrolled, radical (thermally selfinitiated) polymerization can take place (see ref 11; Table 3, entries 12-13).

13 Castro, L.; Kirillov, E.; Miserque, O.; Welle, A.; Haspeslagh, L.; Carpentier, J.-F.; Maron, L. Are solvent and dispersion effects crucial in olefin polymerization DFT calculations? Some insights from propylene coordination and insertion reactions with group 3 and 4 metallocenes. ACS Catal. 2015, 5, 416-425.

14 Schultz, N. E.; Zhao, Y.; Truhlar, D. G. Benchmarking approximate density functional theory for s/d excitation energies in $3 \mathrm{~d}$ transition, metal cations. J. Comput. Chem. 2008, $29,185-189$.

15 Zhao, Y.; Truhlar, D. G. Density functionals with broad applicability in chemistry. Acc. Chem. Res. 2008, 41, 157-167.

16 Becke, A. D. Density-functional thermochemistry. III. The role of exact exchange. $J$. Chem. Phys. 1993, 98, 5648-5652.

17 Burke, K.; Perdew, J. P.; Wang, Y. In Electronic Density Functional Theory: Recent Progress and New Directions; Dobson, J. F., Vignale, G., Das, M. P., Eds.; Plenum: New York, 1998.

Dolg, M.; Stoll, H.; Savin, A.; Preuss, H. Energy-adjusted pseudopotentials for the rare earth elements. Theor. Chem. Acc. Theory Comput. Model. Theor. Chim. Acta 1989, 75, 173-194.

19 Bergner, A.; Dolg, M.; Küchle, W.; Stoll, H.; Preuss, H. Ab initio energy-adjusted pseudopotentials for elements of groups 13-17. Mol. Phys. 1993, 80, 1431-1441.

20 Höllwarth, A.; Böhme, M.; Dapprich, S.; Ehlers, A. W.; Gobbi, A.; Jonas, V.; Köhler, K. F.; Stegmann, R.; Veldkamp, A.; Frenking, G. A set of d-polarization functions for pseudo-potential basis sets of the main group elements Al-Bi and f-type polarization functions for Zn, Cd, Hg. Chem. Phys. Lett. 1993, 208, 237-240. 
21 Marenich, A. V.; Cramer, C. J.; Truhlar, D. G. Universal solvation model based on solute electron density and on a continuum model of the solvent defined by the bulk dielectric constant and atomic surface tensions. J. Phys. Chem. B 2009, 113, 6378-6396.

22 Gaussian 09 Revision D.01; Frisch, M. J.; Trucks, G. W.; Schlegel, H. B.; Scuseria, G. E.; Robb, M. A.; Cheeseman, J. R.; Scalmani, G.; Barone, V.; Mennucci, B.; Petersson, G. A.; others. Gaussian Inc Wallingford CT 2009.

23 Reed, A. E.; Curtiss, L. A.; Weinhold, F. Intermolecular interactions from a natural bond orbital, donor-acceptor viewpoint. Chem. Rev. 1988, 88, 899-926.

24 Clark, D. L.; Gordon, J. C.; Hay, P. J.; Martin, R. L.; Poli, R. DFT study of tris(bis(trimethylsilyl)methyl)lanthanum and samarium. Organometallics 2002, 21, $5000-5006$. 